\title{
دفع النمو الاقتصادي لمصر في ظل تداعيات أزمة كورونا1
}

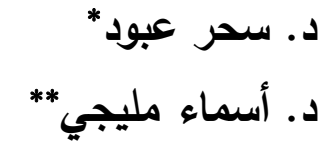

ملخص

تهدف هذه الدراسة الرصد والتحليل للتداعيات المحتملة لأزمة كورونا على النمو الاقتصادي في مصر باعتباره أحد أهم المتغيرات الاقتصادية الكلية وذلك من خلال تحليل هذه التداعيات على مصادر النمو وعلى قطاعاته الاقتصادية المختلفة.

وفي سبيل تحقيق ذللك، ناقشت الدراسة أهم السياسات التي تبنتها مصر لمواجهة التداعيات السلبية لأزمة كورونا على النمو الاقتصادي، كما قدمت الدراسة محاولة لتقدير الأثار المحتملة لتداعيات أزمة كرونا على النمو تلاتئه الاقتصادي، وذلك باستخدام مدخل دالة الإنتاج وبالاعتماد على منهجية ديناميكيات النظم.

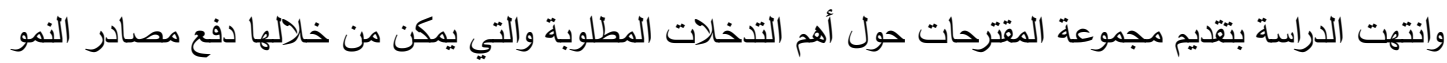
الاقتصادي ومساندة قطاعاته المختلفة أثناء وبعد الأزمة، كما أكدت الدراسة على أن الأزمة الحالية ريما تكون

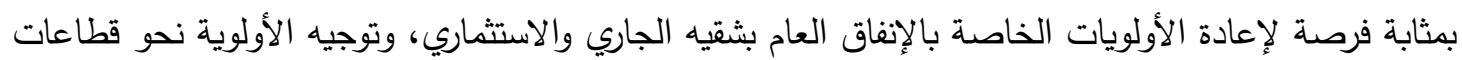
الصحة والتعليم والبحث العلمي والابتكار والاتصالات وتكنولوجيا المعلومات باعتبارهم أهم محفزات النمو في الأجل الطويل.

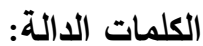
فيروس كورونا- النمو الاقتصادي- السياسات الاقتصادية - دالة الإنتاج - الإنتاجية الكلية للعوامل

\section{Abstract \\ Promoting Egypt's Economic Growth in Light of Corona Crisis}

This study aims to investigate the potentail consequences of Covid-19 on Egyptian economic growth and its main sources as well as the different implications on the various economic sectors.

To achieve that, the study discusses the most important policies which have been adopted by the government to mitigate different repercussions of covid-19 on the economic growth. Also, a quantitative methodology is applied to measure the expected implications of Covid 19 on economic growth using cob-Douglas production function approach by Systems Dynamics methodology. In addition, the study proposed a set of policies to mitigate the impacts of COVID-19 on the economy, and to facilitate strong and fast recovery.

Finally, the study emphasized that the current crisis may be an opportunity to reconsider the priorities of the public expenditure allocation towards sectors of education, health, scientific research and ICT, that are considerd to be main drivers of long run growth.

Key Words:

Coved-19 - Economic Growth - Economic Policies - Production Function- Total Factor Productivity

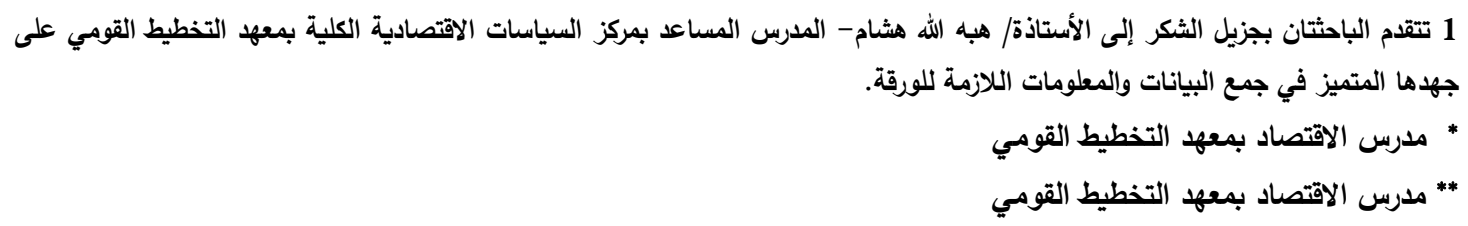




\section{مقدمة}

يواجه العالم اليوم أزمة إنسانية جديدة بدأت في الصين (COVID-19) وانتشرت عبر العديد من دول العالم. ويتوقع أن تفوق في تداعيتها الاقتصـادية والاجتماعية آثار أي أزمة سـابقة بما فيها الأزمة الاقتصادية العالمية لعام 2009/2008 الأمر الذي جعل البعض يشبهها إذا استمرت في الأجلين المتوسـط والطويل بأزمة الكسـاد الكبير (1929- 1939). ولن تقف حدود التأثير لهذه الأزمة على متغيرات الاقتصـاد العالمي فقط بل ستمتد إلى رسم ملامح جديدة للاقتصـاد العالمي بعد الأزمة وبداية ظهور أنماط جديدة في مختلف المجالات لم يكن يتوقع أن تحدث بهذا الثـكل وبهذه السـرعة. فبخلاف الخسـائر الإنسـانية، تسـبيت الأزمة في دخول العالم في مرحلة ركود

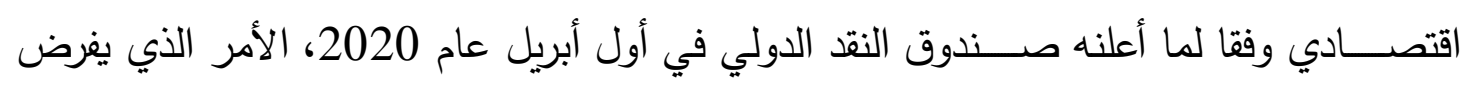

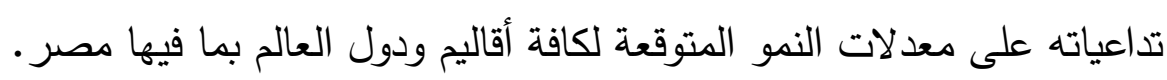

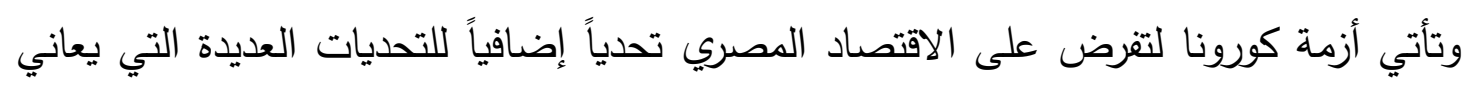

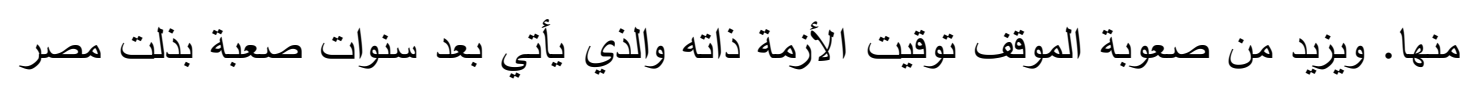
فيها جهوداً كبيرة لمعالجة الاختلالات التي يعاني منها الإقتصاد منذ عقود، وذلك من خلال برنامج للإصلاح الاقتصادي منذ عام 2016 والذي قد بدأ يسفر عن تحسن العديد من مؤشرات الاقتصاد الكلي ومنها معدل النمو الاقتصادي الذي قدر بنحو 5.6\% خلال عام 2018/ 2019 مقابل

$$
\text { 4.2 } 4.2
$$

يعتبر النمو الاقتصادي من أكثر المتغيرات الكلية تأثراً بالأزمات، فقد تراجع خلال الأزمة المالية العالمية ليبلغ 4.7\% لعام 2008/ 2009 مقابل 7\% على مدى العاميين السابقين للأزمة وشهر تراجعا أكبر أثر تداعيات ثورة يناير وما نتج عنها من اضطرابات تسببت في تعطل المصانع

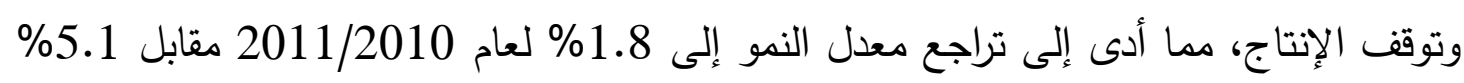

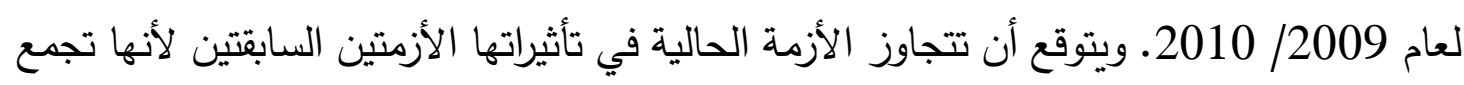
بين صدمتين خارجية وداخلية معا. أهداف الاراسة انطلاقاً من أن معدل النمو الاقتصادي هو أحد المتغيرات الاقتصادية الكلية محل اهتمام صانعي السياسات والاقتصاديين باعتباره أحد المتغيرات الحاكمة للتتمية الاقتصادية كما أكدت الأدبيات وبرهنت عليه التجربة الأسيوية، تهتم الدراسة بتتاول التداعيات المحتملة لأزمة كورونا على النمو 
الاقتصادي في مصر وأهم السياسات التي تبنتها مصر للحد من الآثار السلبية التي فرضتها الأزمة على الاقتصاد المصري. وتأسـيسـاً على أهمية دراســة واختبار أثر العوامل المؤثرة على النمو الاقتصـادي، والتي ترتفع التها أهميتها في وقت الأزمات والتي غالباً ما يصــــها عدم اليقين، تقدم الدراسـة محاولة لتقدير الأثر المتوقع لأزمة كروناعلى النمو الاقتصادي في مصر .

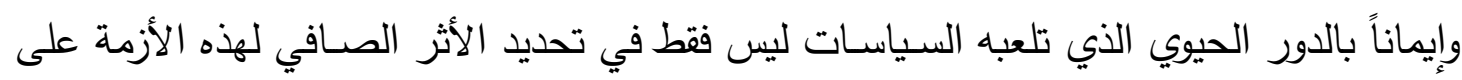

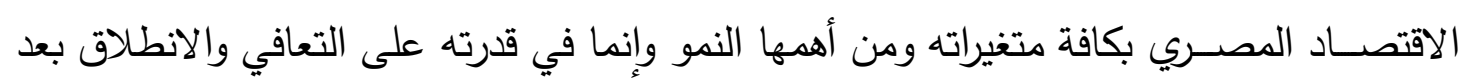

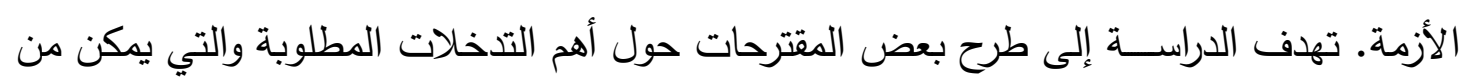
خلالها دفع مصادر النمو ومساندة قطاعاته المحركة أثناء وبعد الأزمة. منهجية الدراسة لتحقيق أهداف الدراسـة تم اســتخدام المنهج الوصـفـي التحليل في توصـيف وتحليل التداعيات

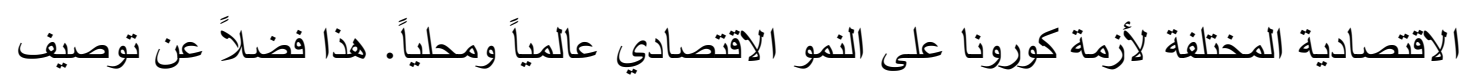
وتحليل وتقييم السياسـات المختلفة التي طبقتها مصر وكذلك دول العالم لتقليل التداعيات السلبية التي خلفتها الأزمة على الاقتصاد. بالإضافة الي استخدام المنهج الكمي في تقدير الأثر المتوقع

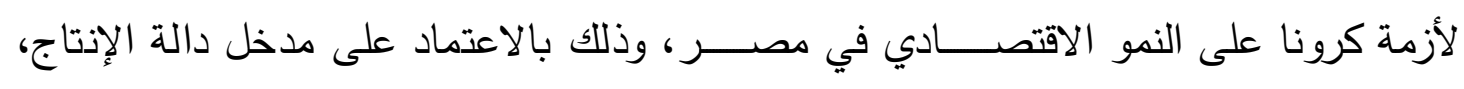
وباستخدام منهجية ديناميكيات النظم (System Dynamics Methodology). محتويات الاراسة تتكون الدراسة من خمسة أجزاء بخلاف المقدمة والخاتمة وهي:

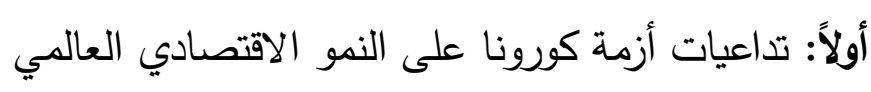

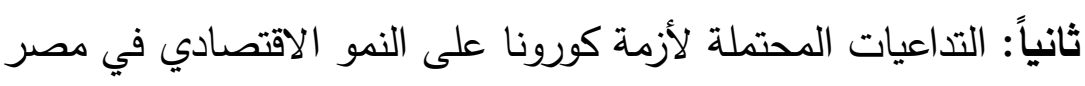

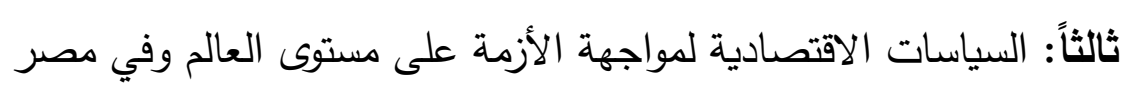
رابعاً: تقدير الأثر المتوقع لأزمة كرونا على النمو الاقتصادي في مصر : مدخل دالة الإنتاج

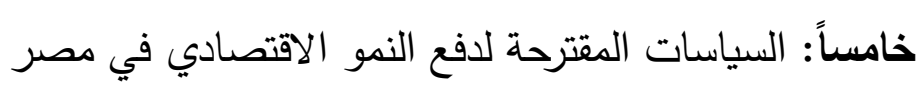
أولاً: تداعيات أزمة كورونا على النمو الاقتصادي العالمي أظهرت تقديرات المؤسسات الدولية أن التداعيات الاقتصادية والاجتماعية لأزمة كورونا قد تتجاوز

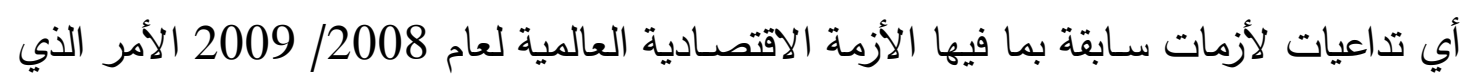


جعل البعض يشبـهـا إذا استمرت في الأجلين المتوسط والطويل بأزمة الكسـاد الكبير (1929-

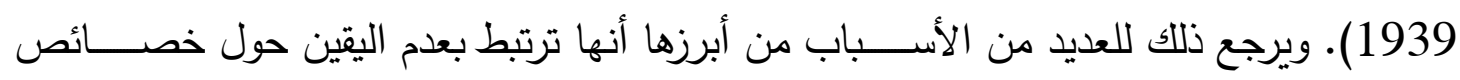

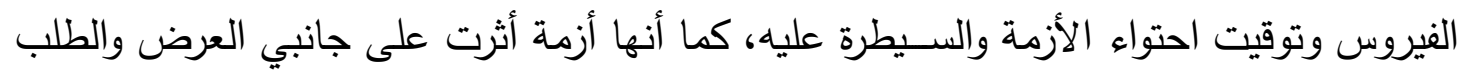

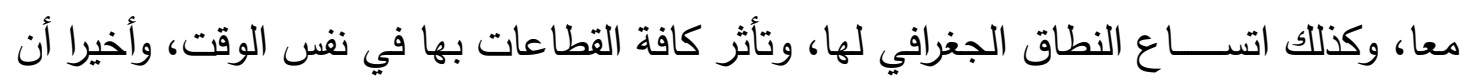
سـبب الأزمة غير اقتصـادي له آثار اقتصـادية واجتماعية بعكس الأزمات السـابقة التي كانت بدايتها اقتصادية أو مالية بالأساس. وقد تســبيت الأزمة في دخول الاقتصــاد العالمي في مرحلة ركود اقتصـــادي وفقا لما أعلنه صــندوق النقد الدولي في أول أبريل عام 2020 الأمر الذي ينعكس ســلبيا على معدلات النمو المتوقعة لكافة أقاليم ودول العالم، والذي كان يحقق معدل نمو بطيء قبل الأزمة الحالية. وقد تفاوتت تقديرات المؤسسـات الدولية لحجم الخسائر على الاقتصـاد العالمي جراء هذه الأزمة. وقد قدرت مؤسســة بلومبرج أن الأزمة تسـببت في خسـائر بلغت 2.7 تريليون دولار 1، بينما قدر بنك التتمية الآســيوي (ADB) حجم الخســائر للناتج العالمي ما بين 77 مليار و 347 مليار . (ADB, 2020) كما قدر مؤتمر الأمم المتحدة للتجارة والتتمية (UNCTAD) أن فيروس كورونا المســــد قد تسـبب في انخفاض الإنتاج العالمي وخسـائر في قطاع التصـدير وحده وصـلت إلى 50 مليار دولار •. وقدرت منظمة السـياحة العالمية حجم الخسـائر بنحو 62 مليار دولار ويتوقع أن تتجاوز 100 كما قدرت منظمة العمل الدولية أن الخسـائر الأولية لهذه الأزمة قد تصـل إلى زيادة المتعطلين بنحو ما يقرب من 25 مليون على مســتوى العالم مقابل 22 مليون عقب الأزمة الاقتصــــادية العالمية 2008/ 2009 وذلك في مـارس لعام 2020 إلا أن متابعه أعداد المتعطلين نتيجة للأزمة تثير إلي تجاوز هذا العدد (ILO,2020). وأخيرا، توقع مؤتمر الأمم المتحدة للتجارة والتتمية UNCTAD تراجع الاســـتــارات الأجنبية المباشـرة على مسـتوى العالم بنسـبة تتراوح ما بين 30- 40\% من قيمتها وتراجع عمليات الدمج والاســـتحواذ بنســـــة تتراوح بين 50- 70\% لعـام 2021/2020 عن مثيلتهـا في عـام $.2021 / 2019$ 
أما عن تأثير الأزمة على معدل النمو الاقتصادي العالمي فقد بادرت كافة المنظمات الدولية بإصدار توقعاتها عن النمو الاقتصادي لعام 2020 ومنها مؤسسة ماكينزي (MC kinesy)، والتي لاكي رصدت ثلاث سيناريوهات محتملة لتأثير الأزمة على الاقتصاد العالمي وهي: السيناريو الأول الخاص بسرعة التعافي، والذي يتوقع أن يحدث انخفاض طفيف في معدل النمو الاقتصادي العالمي لعام 2020 من 2.5\% إلى 2\%، بينما يتوقع السيناريو الثاني الخاص بالركود الاقتصادي تراجعاً

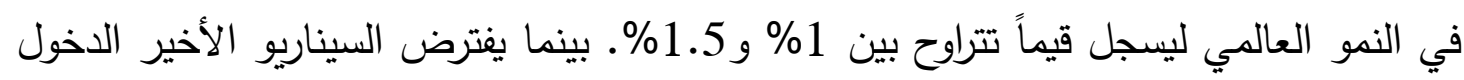
في ركود عالمي مزمن نتيجة الوباء، وبهذا السيناريو لن يتجاوز النمو الاقتصادي 0.5\% وقد يتحول إلى معدلات سالبة (MckinseyCompany, 2020) وعلى مستوى الثرق الأوسط وشمال أفريقيا تشير التوقعات إلى تراجع معدل النمو الاقتصادي في ظل السيناريو الأول من 2.39 إلى 1.95\% لعام 2020، وفي ظل السيناريو الثاني إلى 1.21\% ومعدلات سالبة في السيناريو الثالث. كما توقعت منظمة التعاون الاقتصادي والتتمية (OECD) أن ينخفض النمو الاقتصادي العالمي ليصل إلى 2.4\% لعام 2020 مقابل 2.9\% في العام السابق، ومع انتشار الفيروس عالمياً واشتداد حدته قد يصل إلى 1.5\% وهو معدل لم يشهده حتى وقت أزمة 2009/2008.

(OECD, 2020)

وقد خفض صندوق النقد الدولي (IMF) توقعاته للنمو الاقتصادي العالمي في أبريل لعام 2020 ليصل -3\% في عام 2020، وهو أسوأ بكثير مما ترتب على الأزمة المالية العالمية في 2008-

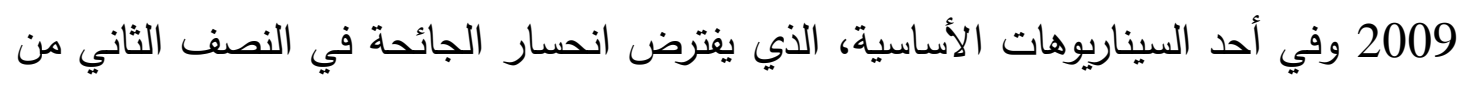
عام 2020 وإمكانية تخفيف جهود الاحتواء بالتدريج، من المتوقع أن ينمو الاقتصاد العالمي بمعدل \%,8 في عام 2021 مع عودة النشاط الاقتصادي إلى طبيعته، بمساعدة الدعم المقدم من السياسات. وعلى مستوى الدول يتوقع أن يكون تراجع النمو أكبر في الدول المتقدمة (معدل نمو 6.1\%) أما الدول الناشئة والنامية يتوقع تراجعا أقل (معدل نمو -1\%1\%) (IMF,2020). هذا ويتم مراجعة كافة التقديرات السابقة بشكل دوري في ضوء المستجدات المرتبطة بانتشار الفيروس وإمكانية السيطرة عليه. 
ثانياً: التداعيات المحتملة لأزمة كورونا على النمو الاقتصادي في مصر لن ترتبط تداعيات أزمة كورونا على النمو في مصر فقط بظهور الفيروس بها، وإنما يتوقع تأثر النمو منذ ظهوره في الصين وانتشاره في الدول الأوروبية والعربية والولايات المتحدة الأمريكية باعتبارهم شركاء رئيسين لمصر • وبالتالي سوف تتأثر متغيرات الاقتصاد المصري باضطراب سلاسل التوريد العالمية، وانخفاض الطلب العالمي، وتراجع معدل الاستثمار ، وتوقف الأنشطة الاقتصادية في العديد من دول العالم، وتراجع معدلات نمو التجارة الدولية نتيجة الإجراءات الاحترازية العديدة التي تبنتها مختلف الدول لمواجهة الفيروس. لذا فمن المتوقع أن تظهر آثار الأزمة على المتغيرات الاقتصادية الكلية في مصر اعتباراً من الربع الثالث من العام المالي 2020/2019 حيث بداية تداعيات الأزمة على الصين ثم العالم ثم مصر

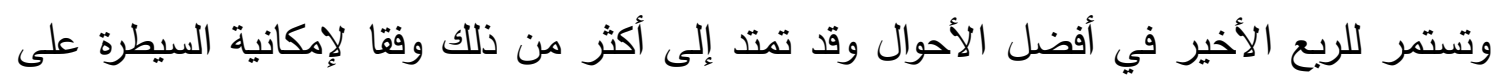
الفيروس عالميا ومحليا. ويتوقع أن يكون للازمة تداعيات عديدة على معدل النمو الاقتصادي من منظور الطلب والعرض

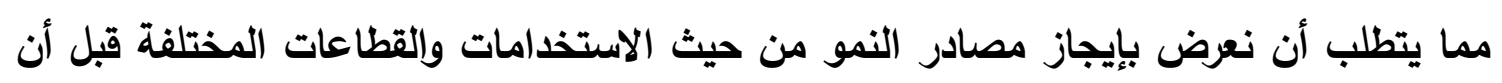
نبدأ بتوقع تداعيات الأزمة عليه. 1 النمو الاقتصادي قبل أزمة كورونا تأتي جائحة كورونا لتفرض على الاقتصاد الدصري تحدياً إضافياً للتحديات العديدة التي يعاني منها الاقتصاد المصري. ويزيد من صعوبة الموقف توقيت الأزمة ذاته والذي يأتي بعد سنوات صعبة

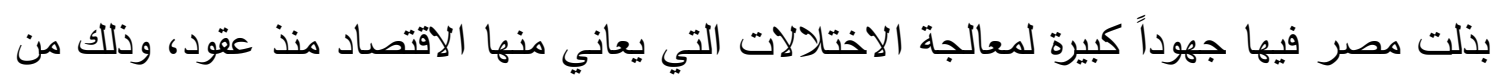
خلال برنامج للإصلاح الاقتصادي بدأ منذ 2016 بالشراكة مع صندوق النقد الدولي. وقد أسفرت

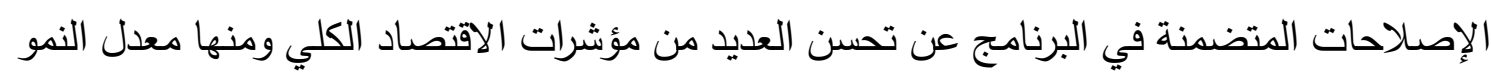
الاقتصادي الذي بلغ 5.6 \% خلال عام 2019/2018 مقابل 4.2\% في عام 2017/2016، وذللك كما يتضح من الثكل التالي. 
شكل (1): تطور معدل نمو الناتج المحلي الإجمالي الحقيقي

خلال الفترة (2007/2006 - 2019/2018)

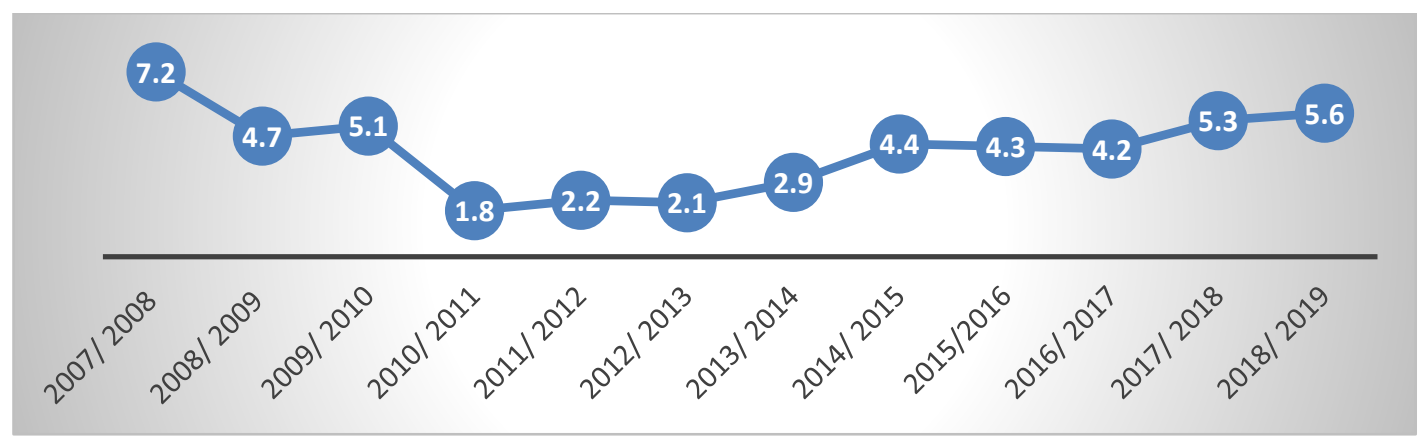

المصدر: وزارة التخطيط والتتمية الاقتصادية، تقارير متابعة الاداء الاقتصادي والاجتماعي، أعداد مختلفة.

تم تقدير حجم الناتج المحلي الإجمالي بتكلفة عوامل الإتتاج (بالأسعار الجارية) بنحو 5.170 تريليون دولار ، 70\% منه للقطاع الخاص و 30\% للقطاع العام وذلك للعام المالي 2019/2018. أ.على مستوى الاستخدامات بلغ الاستهلاك الإجمالي 4.7 تريليون جنيه خلال العام المالي 2019/2018 وبالتالي يستحوذ الاستهلاك على 90\% من مكونات الناتج المحلي الإجمالي (81\% للاستهلاك الخاص و9\%

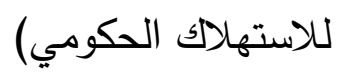

على الرغم من أن الطلب الاستهلاكي النهائي ظل هو المصدر الرئيسي للناتج الدحلي الإجمالي خلال العقد الماضي إلا أن أهميته شهدت تراجعا اعتبارا من العام المالي 2018/2017 مقابل زيادة أهمية الاستثمار لتمثل ما يزيد عن 40\% من النمو المتحقق، وارتفعت المساهمة الإيجابية لصافي الصادرات في النمو كما يتضح من الثكل التالي. شكل(2): مصادر النمو أخر ثلاث سنوات مالية

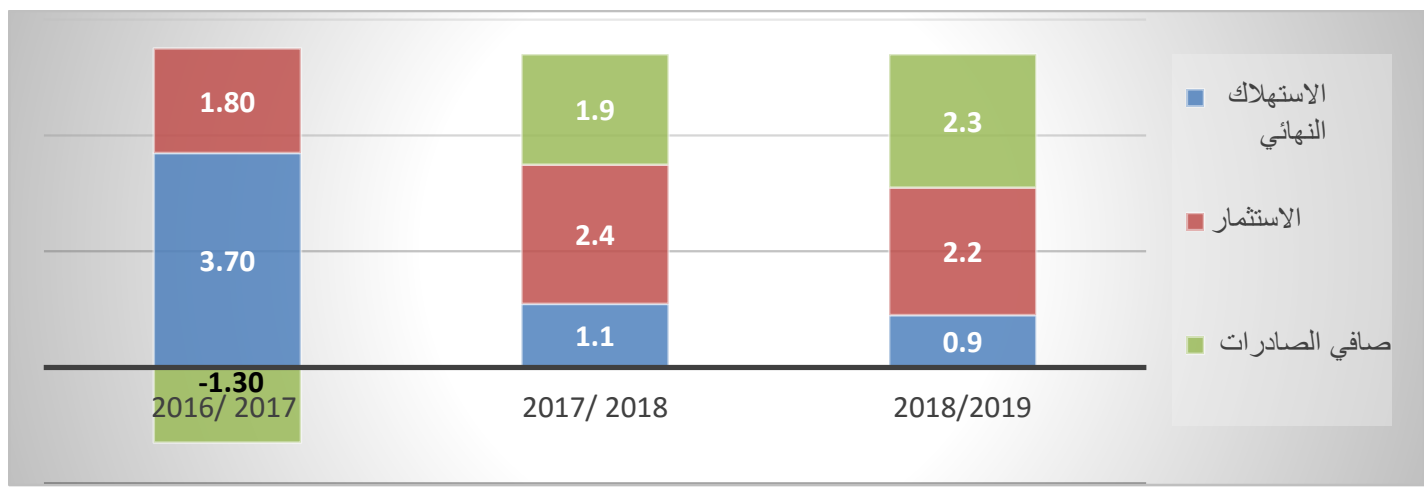

المصدر: البنك المركزي المصري، (2020)،" النشرة الاقتصادية الشهرية "، مارس. 
وعلى مستوى الاستثمارات، تقدر الاستثمارات الكلية بنحو 970 مليار جنيه عام 2019/2018

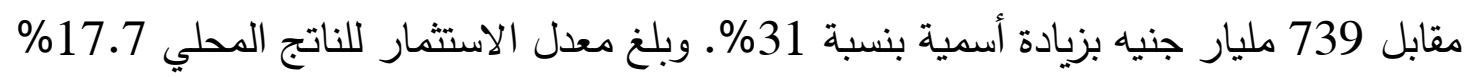
مقابل 16.7\% في العام السابق. وبمقارنة معدل الاستثمار 17.7\% بمعدل الادخار 6.2 \% يتضح أنه مازال هناك فجوة تقدر بأكثر من 10 نقاط مئوية، مما يؤكد على الحاجة لمزيد من دفع معدل النمو الاقتصادي ومستونات الدخول الحقيقية وفي نفس الوقت شدة الحاجة لجذب الاستثمار الخاص بشقيه المحلي والأجنبي. بينما يقدر الاستثمار الخاص بنحو 484.2 مليار جنيه خلال عام 2019/2018 مقابل 316.4 مليار في العام السابق بزيادة 53\%. ويمثل الاستثمار الخاص 51\% من إجمالي الاستثمارات الكلية المنفذة خلال العام المالي نفسه. شكل(3): هيكل الاستثمارات الكلية للعام المالي 2018/ 2019
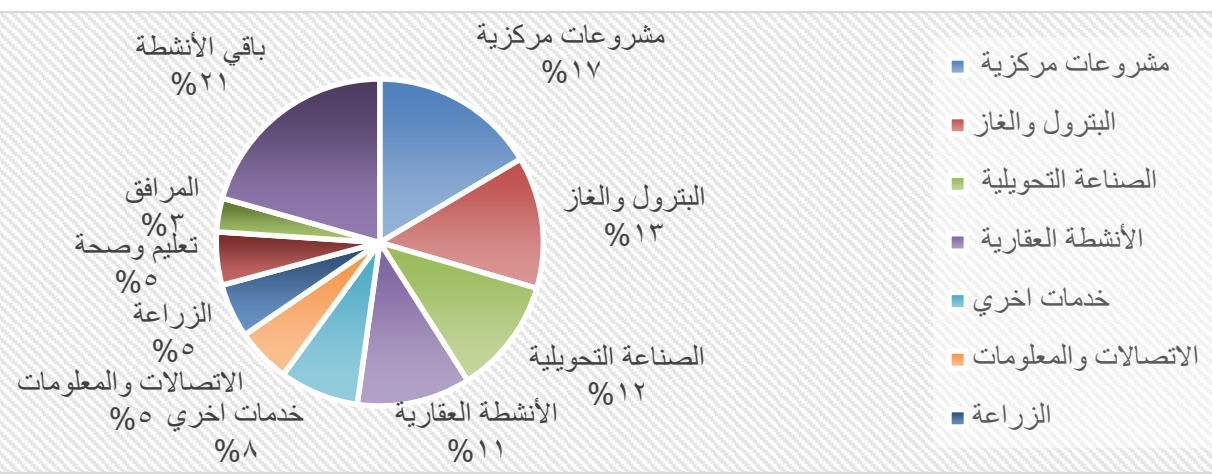

المصدر: البنك المركزي الدصري، (2020)،" النشرة الاقتصادية الشهرية "، مارس.

ويتضح تركز الاستثمارات الكلية والعامة في المشروعات المركزية وأنشطة البترول والغاز والأنشطة العقارية يليها الصناعة التحويلية بينما تتخفض نسب الاستثمار إلى أقل من 5\% لألثطة التعليم والصحة والزراعة وهو ما قد يفسر تواضع معدل نمو القطاعات الإنتاجية نظراً لتدني الاستثمارات الموجهة إليها.

وأخيراً، بلغت الاستثارات الأجنبية المباشرة نحو 8.2 مليار دولار خلا العام المالي 2019/2018 مقابل 7.7 مليار دولار في العام السابق. وكانت الولايات المتحدة والمملكة المتحدة والإمارات أكبر ثلاث دول تستثمر مباشرة في مصر • (البنك المركزي المصري، معابل وفقاً لوزارة التخطيط والتتمية الاقتصادية تتركز ثلثي الاستثمارات الأجنبية المباشرة في الاستخراجات والبترول. 
ب.على مستوى القطاعات

حققت خمسة قطاعات معدلات نمو تفوق متوسط معدل نمو الناتج المحلي الإجمالي. ضمت هذه القطاعات السياحة والاتصالات والاستخراجات والتشييد والبناء وقناة السويس كما يتضح من الشكل التالي، وعلى الرغم من ارتفاع معدل نمو هذه القطاعات إلا أن مساهمتها في الناتج المحلي الإجمالي لم تتجاوز 25\%. شكل(4): معدلات النمو القطاعية خلال العام المالي 2019/2018

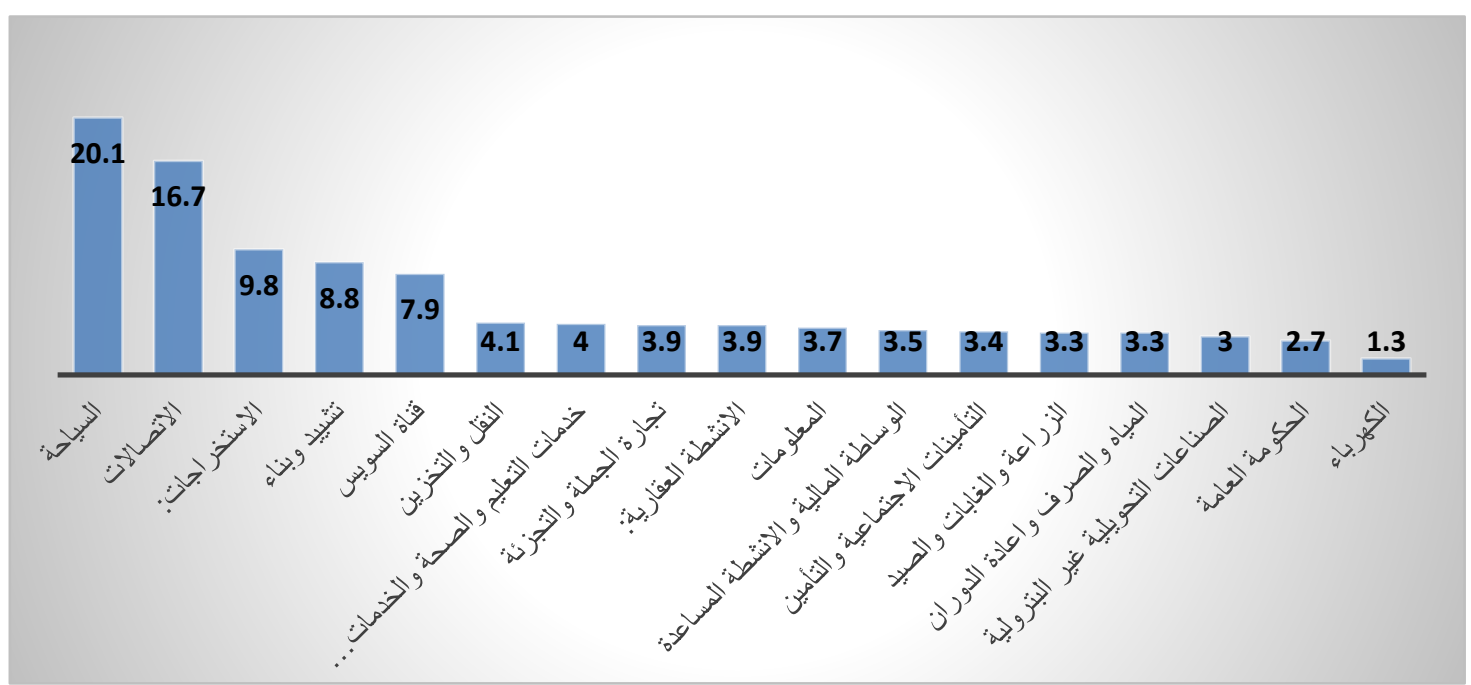

المصدر : البنك المركزي المصري، (2020)،" النشرة الاقتصادية الثهرية "، مارس. بينما شهد قطاعي الصناعة والزراعة معدلات اقل من متوسط معدل النمو الاقتصادي لعام 2019/18 على الرغم من كبر نصيبهما في الناتج والتي تقدر بنحو 13\% للصناعة و 11\% للزراعة. ويعتبر ذلك تراجعا عن أدائها في فترات سابقة؛ فقد حقق قطاع الصناعات التحويلية في العام المالي 2010/2009 أي عقب الأزمة المالية العالمية معدل نمو 5.3\% ونسبة مساهمة نحو 16\% من الناتج المحلي الإجمالي. 2. التداعيات المحتملة لأزمة كورونا على النمو توقعت العديد من المؤسسات المحلية والدولية تراجع معدل نمو الناتج المحلي الإجمالي في مصر نتيجة لتداعيات الأزمة على مصادر النمو والقطاعات المحركة. بينما توقع صندوق النقد الدولي أن النمو لن يتجاوز 2\% خلال عام 2020 ثم يتعافى ليصل إلى 2.8\% في العام التالي 2021. ووفقاً لوزارة التخطيط والتتمية الاقتصادية يتوقع تراجع معدل النمو الاقتصادي من 5.6\% للعام المالي 2019/2018 الي 4.2\% عام 2020/2019 أما تقديرات النمو الاقتصادي للعام المالي 
2021/20 فتتم وفقا لسيناريوهاين: السيناريو المتفائل الذي يرجح انتهاء السيطرة الكاملة على الفيروس بحلول يونيو لعام 2020 وفيه ينخفض النمو الاقتصادي إلى 3.5\% في العام 2021/2020. بينما يقوم السيناريو المتشائم على استمرار الجائحة حتى نهاية عام 2020 وفيه ينخفض النمو الاقتصادي إلى 2\% للعام المالي 2021/2020. (وزارة التخطيط والتنمية الاقتصادية، 2020)

وقدرت مؤسسة (International Food Policy Research Institute: IFPRI) تراجع معدل النمو الاقتصادي ليتراوح بين 2.1\% - 4.8\% في عام 2020 نتيجة تراجع السياحة وتحويلات العاملين وإيرادات قناة السويس فقط بنسبة 10\%- 15\% خلاد عام 2020/2019 عن قيمتها في عام 2019/2018 وذلك وفقا لمدي التشاؤم والتفاؤل بشأن الفيروس. (IFPRI, 2020) وأخيراً، وضع المركز المصري للدراسات الاقتصادية سيناريوهين للنمو أحدها السيناريو المتفائل والذي يشهـ تراجع النمو إلى 3.5\% عام 2020 ثم يتعافى إلى 4.7\% عام 2021. بينما وفقا

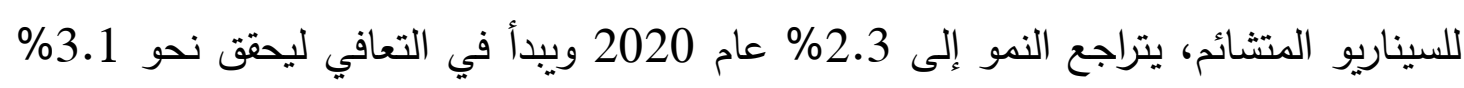
عام 2021. (المركز المصري للدراسات الاقتصادية، 2020) ونعرض فيما يلي تحليلاً للتداعيات المحتملة على مصادر النمو من حيث الاستخدامات والقطاعات المختلفة وفقا لأحدث البيانات المتاحة: تأثر مصادر النمو بالأزمة يتوقع أن تؤدي الإجراءات الاحترازية التي تم اتخاذها للسيطرة على الفيروس من حظر تجول

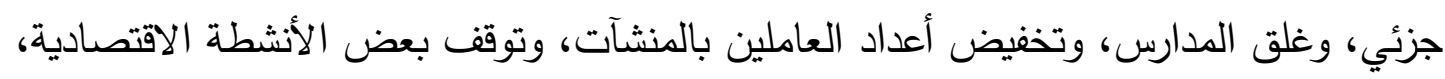

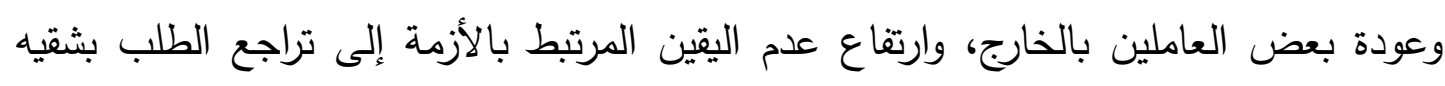

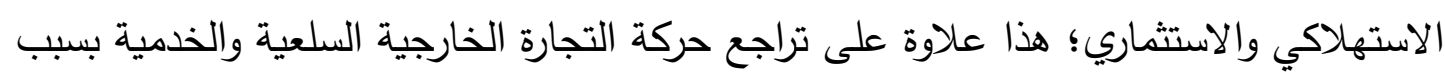
تراجع حركة التجارة الدولية. 
يتوقع أن يُسهم التراجع المحتمل لتحويلات العاملين بالخارج 1 وكذللك للإيرادات السياحية2 بالإضافة إلى تراجع إيرادات قناة السويس في تراجع الدخول وبالتالي تراجع مستوبات الاستهلاك حتى إذا لم يكن هناك توقف لحركة النشاط الاقتصادي داخلياً.

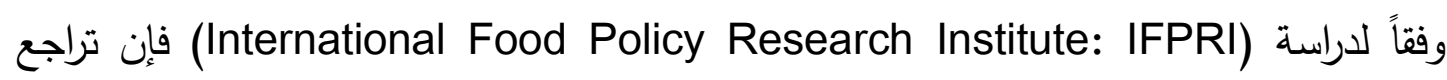
الثلاث متغيرات فقط يتوقع أن يؤدي لتراجع الاستهلاك العائلي ليتراوح ما بين 153- 180 جنيها للفرد / شهريا أي فقد نسبة 9- 10.6\% من إجمالي الدخل. تشمل هذه المتغيرات تراجع الإيرادات السياحية وتحويلات العاملين وإيرادات قناة السويس بنسبة 10- 15\%. وتوصلت الدراسة إلى الى تأثر الاستهلاك العائلي بتراجع الإيرادات السياحية يليها تراجع تحويلات العاملين بالخارج يتجاوز بكثير تأثيرات إيرادات قناة السويس. كما أن تأثر الفقراء في الريف يرتبط بتراجع التحويلات بالأساس بينما تأثر فقراء الحضر يرتبط بتراجع الإيرادات السياحية.

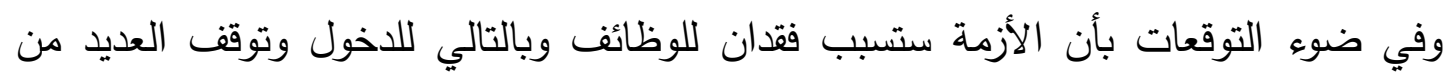
المشروعات خاصة متتاهية الصغر والصغيرة وكذلك أسر العاملين بالخارج اللذين ستتأثر التحويلات لديهم، فيتطلب الأمر توفير حد أدني من الدخل لهذه الفئات، وخاصة وأن الشرائح الدنيا تتسم بارتفاع ميلها الحدي للاستهلاك. وتتوقع وزارة التخطيط والتتمية الاقتصادية أن يصل الاستهلاك الإجمالي إلى 5.5 تريليون جنيه عام2020/2019 بزيادة قدرها تريليون جنيه عن العام السابق، ثم يرتفع مرة أخرى إلى تريلون جنيه للعام 2021/2020 وبالتالي يظل الاستهلاك هو المحرك الرئيسي للنمو بعد الأزمة.

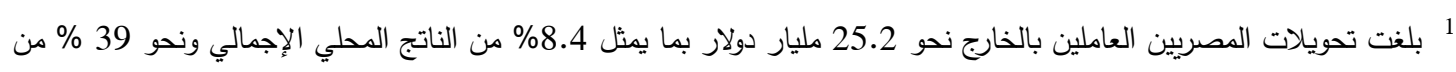

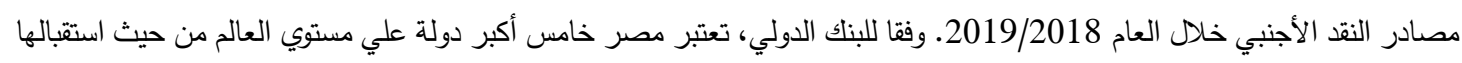

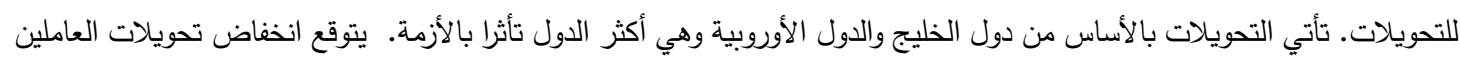

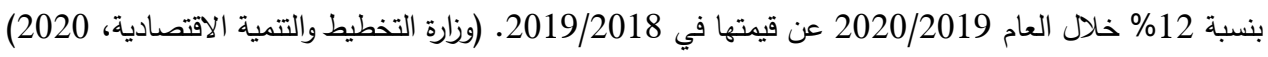

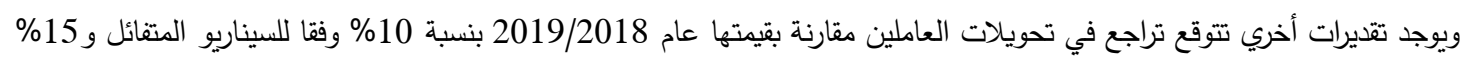
وفقا للسيناريو المتثائم. (المركز المصري للدراسات الاقتصاديادية، 2020)

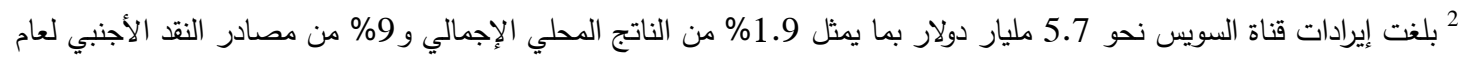

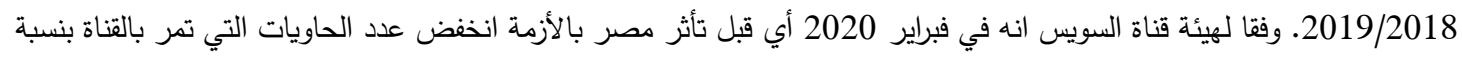

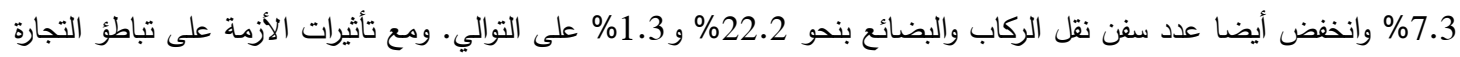

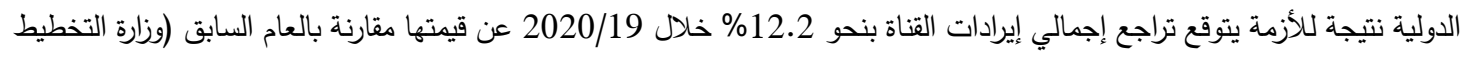

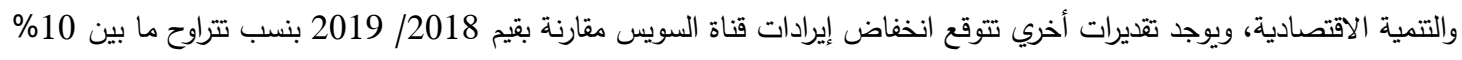

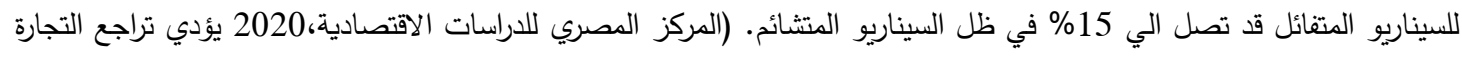
العالمية بمقدار 1\% الي انخفاض الإيرادات من قناة السويس بنحو 
وعلى مستوى الاستثمارات وفي ظل ارتفاع عدم اليقين سواء المرتبط بالأزمة و /أو المرتبط بالسياسات التي سيتم تبنيها يتوقع تراجع الاستثمارات الخاصة وهو ما قد حدث أثناء الأزمة الاقتصادية العالمية لعام 2009/2008 حيث تراجعت الاستثمارات الخاصة من 129 مليار جنيه قبل الأزمة إلى 95.5 مليار في عام الأزمة بنسبة تراجع 26\% وعوض هذا التراجع ارتفاع الاستثمارات العامة عام الأزمة إلى 104.5 مليار مقابل 71.5 في العام الذي يسبق الأزمة أي لي

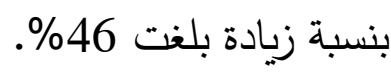
وتتوقع وزارة التخطيط والتتمية الاقتصادية تراجع الاستثمارات الخاصة من 484 مليار جنيه عام

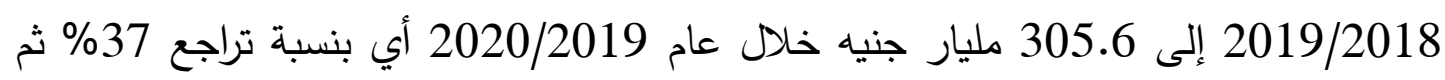
تتراجع مرة أخرى بنحو 53\% بحيث لا تتجاوز 145 مليار جنيه لعام 2021/2020. ولتعويض كام

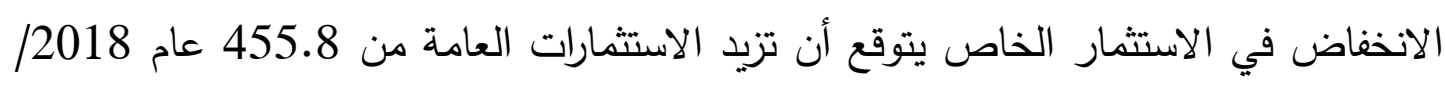

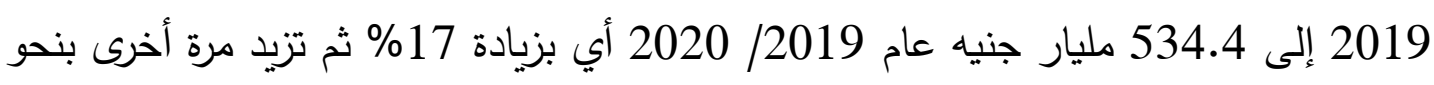
11\% لتبلغ 595 مليار جنيه عام 2020/ 2021. (وزارة التخطيط والتنمية الاقتصادية، 2020) وأخيراً، نظراً لتراجع الطلب الخارجي والنشاط الاقتصادي في الخارج يتوقع تراجع الاستثمار

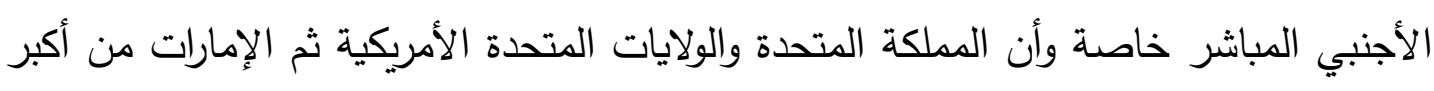
المستثمرين في مصر ومن أكثر المتأثرين بالفيروس. وقد سبق وأن شهد الاستثمار الأجنبي

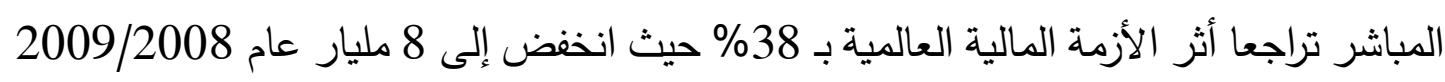

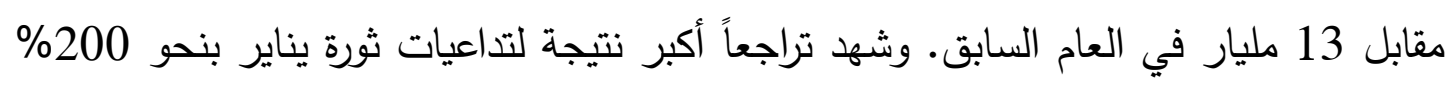
حيث بلغ 2.2 مليار في عام 2011/2010 مقابل 6.8 مليار في العام السابق. وتتوقع وزارة التخطيط والتتمية الاقتصادية تراجع صافي الاستثمار الأجنبي المباشر من 8.2 مليار دولار عام 2019/2018 إلى 6.5 مليار دولار عام 2019/ 2020 ثم يتعافى ليصل إلى دماري 7.5 مليار دولار عام 2021/2020. (وزارة التخطيط والتتمية الاقتصادية، 2020)

\section{صافي الصادرات}

يعتبر الثركاء التجاريين الرئيسيين لهصر وهم الصين والاتحاد الأوروبي ودول الخليج والولايات

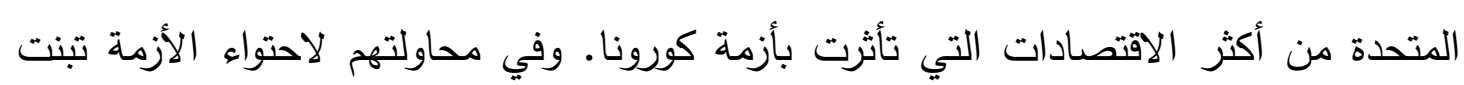

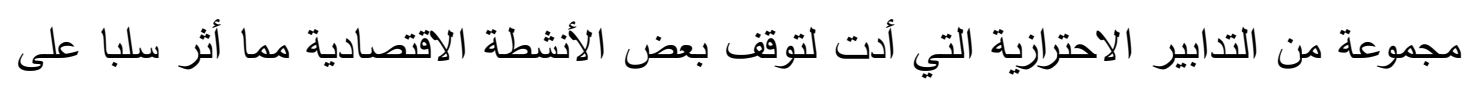
التجارة الخارجية السلعية والخدمية. 
التجارة الخدمية: توقفت التجارة الخدمية خاصة أنشطة السياحة نتيجة غلق المجال الجوي وكذلك عودة المبعوثين من الخارج سواء للتعليم أو لتلقي العلاج. يتوقع أن تئثر الأزمة سلبا بشكل مباشر علي صافي الميزان التجاري الخدمي والذي حقق الميزان الخدمي فائضا بلغ 13 مليار دولار عام

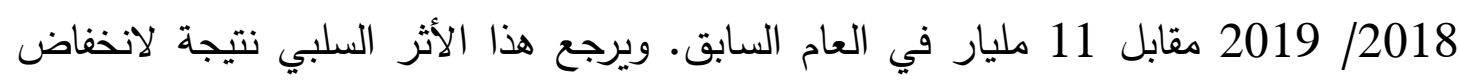
إيرادات السياحة وقناة السويس والذي يمثلا معا 75\% من إجمالي متحصلاته وتبلغ قيمة إيراداتهما 12.6 و 5.7 مليار دولار على التوالي. التجارة السلعية: تعاني مصر من عجز مزمن في الميزان التجاري بلغ 38 مليار دولار بما يمثل 12.6 من الناتج المحلي إجمالي عام 2018/ 2019 والأثر النهائي للازمة على العجز سيكون محصلة الأثر على جانبيه معا. فقد بلغت الصادرات السلعية 25.5 مليار دولار عام 2019 ويستحوذ الاتحاد الأوروبي على 42 منها و23\% للدول الآسيوية غير العربية و13\% للولايات المتحدة و9.4 \% للسعودية.1 ويتوقع تراجع الطلب الخارجي وبالتالي الصادرات المصرية بما لا يقل عن 25\% خلال 2020 سواء للاتحاد الأوروبي أو الولايات المتحدة الأمريكية مع حتمية حسوث تأخر في التسليم نتيجة American Chamber of Commerce in ) تثديد إجراءات الدخـول في ظل الأزمـة (Egypt,2020 وعلى مستوى الواردات، فقد بلغت نحو 65 مليار دولار عام 2019 منها 34\% تأتي من الاتحاد الأوروبي بينما 19\% من الواردات المصرية جاءت من الصين و8.4\% من الولايات المتحدة الأمريكية. كذلك يتوقع أن تشهد الواردات انخفاضا نتيجة للأزمة وحيث أن هيكل الواردات المصرية يتسم بعدم المرونة لأن أغلبه سلع أساسية من غذاء وبترول وسلع وسيطة ومستلزمات إنتاج مما لا شك فيه أنه سيترتب على انخفاض الواردات عجز في مستلزمات الإنتاج لصناعات متعددة ومنها الإلكترونيات والملابس الجاهزة وغيرها. كما تفاوتت تقديرات تراجع المجموعات السلعية المختلفة للصادرات والواردات؛ وهو ما يحتاج مزيد من التفصيل إلا أنه من المؤكد أن أي تراجع في التجارة سيؤثر سلباً على التثغيل وبالتالي الدخول ومن ثم الطب النهائي.

1 بN Comtrade Statistics, Trade map 
تأثر القطاعات الاقتصادية بالأزمة يتباين أثر الأزمة على القطاعات الاقتصادية المختلفة فبينما تشهد العديد من القطاعات تراجعا في

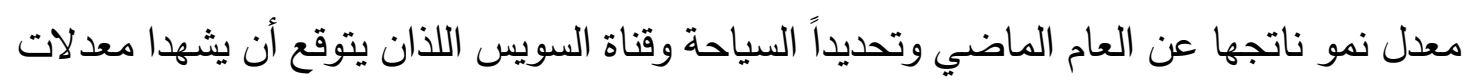
نمو سالبة نتيجة للأزمة ثم الصناعات التحويلية. بينما يوجد قطاعات أخري صاعدة يتوقع أن

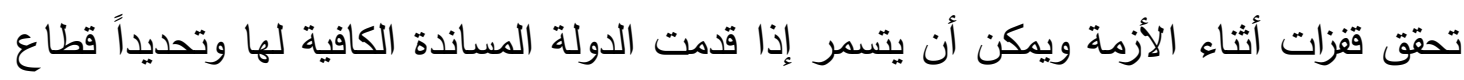
الاتصالات وتكنولوجيا المعلومات. وفيما يلي نعرض بشكل موجز نبذه عن تأثر قطاعي السياحة والصناعات التحويلية كنماذج للقطاعات المتضررة وقطاع الاتصالات وتكنولوجيا المعلومات كنموذج للقطاعات المستفيدة. السياحة يعتبر قطاع السياحة من أكثر القطاعات المتضررة مباشرة من الأزمة، حيث تراجعت الحجوزات بنسبة 80\% خلال يناير - مارس 2020 عن نسبتها في الربع المناظر ـ وتساهم السياحة والطيران بنحو 12\% من الناتج المحلى الإجمالي ويقوم بتوظيف نحو 10\% من إجمالي القوى العاملة

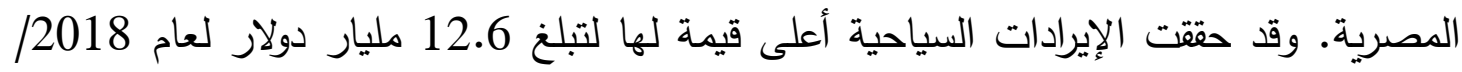
2019 وهو ما يمثل 2.4 \% من الناتج المحلي الإجمالي. (البنك المركزي المصري، 2020) ووفقاً لتقديرات وزارة السياحة والطيران فإن الأزمة تحمل قطاع السياحة بخسائر تقدر بنحو مليار دولار شهرياً. هذا فضلاً عن تحمل قطاع الطيران خسائر تقدر بنحو 2.25 مليار جنيه نتيجة تعليق حركة الطيران وفقاً لتصريحات نشرت لوزارة الطيران المدني. يتوقع تراجع الإيرادات السياحية بنحو 6 مليار دولار خلال عام 2019/ 2020 لتبلغ إجمالي الإيرادات 10.7 مليار دولار مقابل إيرادات متوقعة قبل الأزمة 16.7 مليار لنفس العام أي تراجع بنسبة 35\% خلال عام 2019/ 2020 عن قيمتها في العام السابق (المركز المصري للدراسات الاقتصادية، 2020). كما تتوقع وزارة التخطيط تراجع معدل نمو قطاع السياحة من 20.1\% عام 2019/2018 الي -15.4 عام 2020/2019 ثم تتراجع بمعدل أقل خلال العام التالي - 6\% لعام $.2021 / 2020$ 
ولن تقف التأثرات السلبية عند قطاع السياحة وحده بل ستمتد إلى القطاعات المرتبطة به؛ حيث يعد قطاع السياحة من القطاعات شديدة التشابك مع القطاعات الأخرى (الغذائية، المنسوجات والمفروشات، المواصلات، التشييد والبناء، وغيرهم). الصناعات التحويلية يعتبر أحد أهم الأنشطة الاقتصادية من حيث مساهمته في الناتج أو التشغيل أو التصدير • حيث يقدر الناتج المحلي الصناعي بنحو 657 مليار جنيه عام 2019/2018، كما تبلغ مساهمة الصناعات التحويلية في الناتج المحلي الإجمالي 13\% بمعدل نمو 3\% خلال العام المالي 2019/2018 مقابل 16\% متوسط مساهمة في السنوات السابق. ويرجع ذلك إلى تواضع نصيب القطاع من إجمالي الاستثمارات نحو 11.4 \% من إجمالي الاستثمارات وهو نصيب مساوي للاستثمارات في الغاز الطبيعي ومقارب لنصيب الأنشطة العقارية. تتوقع وزارة التخطيط تراجع معدل نمو القطاع من 3\% عام 2019/2018 إلى 2.4\% عام 2020/2019 ثم التعافي التدريجي ليبلغ معدل نموها 3.3 \% عام 2021/2020. وقد بلغت الصادرات الصناعية1 16.7 مليار دولار بما يمثل ما يتجاوز 60\% من إجمالي الصادرات المصرية. ويستحوذ الاتحاد الأوروبي على 34\% والدول العربية 30\% بينما 16\% للدول الآسيوية غير العربية لعام 2019. بينما بلغت الواردات الصناعية 53.8 مليار دولار تمثل 80\% من إجمالي الواردات المصرية لعام 2019. وتأتي 41\% من الواردات من الدول الآسيوية غير العربية وغالبيتها من الصين

$$
\text { و 33 من الاتحاد الأوروبي لعام } 2019 .
$$

تعتمد الصناعة في مجملها على مستلزمات الإنتاج الأولية والوسيطة المستوردة وتمثل 44\% من إجمالي الواردات المصرية لعام 2019. (وزارة التجارة والصناعة، 2019) وبالتالي فإن نقص المستلزمات سوف يؤثر على قدرة المصانع على استمرار الإنتاج خاصة مع تأثر العمال بالفيروس وانتشار الإصابات وبالتالي غلق المصانع وفي نفس الوقت في ظل انخفاض الطلب العالمي نتيجة للأزمة يتوقع تراجع الصادرات الصناعية التي تمثل 57\% من إجمالي الصادرات المصرية. 


\begin{tabular}{|c|c|c|c|}
\hline المتيناريو & الميناريو & السيناريو المتفائل & \\
\hline 639.4 & 649 مليار جنيه & 657 مليار جنيه & قيمة الناتج الصناعي \\
\hline$\% 56^{-}$ & $\% 28-$ & $\begin{array}{c}\text {-14\% عن المعدل عام } 2019 \\
2019\end{array}$ & معدل نمو الصادرات \\
\hline$\% 30-$ & $\% 15^{-}$ & -7\% عن المعدل عام 2019 & معدل نمو الواردات \\
\hline
\end{tabular}

المصدر: المركز المصري للدراسـات الاقتصـادية، رأي في أزمة: الصناعات التحويلية مجتمعة، العدد 6، أبريل .2020

ومن المعروف ان تأثر الصناعات التحويلية بشكل عام سينسحب على العديد من الأنشطة الاقتصادية الأخرى نظراً للروابط الأمامية والخلفية للقطاع مع باقي القطاعات، علاوة على أثرها على التشغيل أيضا. ويجدر الإثارة إلى أن مدى وشدة تأثير الأزمة يتفاوت وفقاً للنشاط الصناعي الفرعي فهناك صناعات سوف تتتش مع الأزمة ومنها المستحضرات الصيدلانية والدوائية وإنتاج مستلزمات المستشفيات وكذلك بعض فروع الصناعات الغذائية بينما تعاني صناعات أخري مثل السيارات والصناعات الهندسية والملابس لذا فهي تستحق دراسة منفصلة. قطاع الاتصالات حقق القطاع أعلى معدل نمو سنوي كما سبق أن أشرنا نحو 16.7\% عام 2019/2018. ويرجع ارتفاع معدل نمو القطاع إلى توجه الدولة نحو الثمول المالي والتحول الرقمي؛ حيث بلغ عدد مستخدمي الإنترنت عبر المحمول 39 مليون مستخدم بمعدل نمو سنوي 11 \%. وقد أدت الأزمة إلى التعجيل بالتحول الرقمي في قطاعات التعليم والخدمات المالية والتجارة الإكترونية؛ فبصدور قرار تعليق الدراسة، وفرض حظر التجوال الجزئي، والتوسع في تطبيق الإجراءات الاحترازية واتجاه المؤسسات الحكومية والخاصة للسماح لموظفيهم بأداء مهامهر من المنزل عبر الإنترنت تزايد الطلب بشدة على شبكات الإنترنت. (المركز المصري للدراسات 
لذا تتوقع وزارة التخطيط والتنمية الاقتصادية ارتفاع نمو ناتج هذا القطاع عند 19\% مع زيادة مساهمته في الناتج لتصل الإلى 12\% عام 2020/2019 مقابل 7.5\% عام 2019/2018. ثالثا: السياسات الاقتصادية لمواجهة الأزمة على مستوى العالم وفي مصر 1. السياسات على مستوى العالم

فرضت أزمة كورونا على الدول بمختلف مستوباتها التتموية تحديات اقتصادية واجتماعية غير مسبوقة، الأمر الذي دفع العديد من المنظمات الدولية لتقديم حزم تحفيزية لدعم جهود أعضاؤها في الحد من انتشار الفيروس ومواجهة تداعياته من جانب1. (صندوق النقد العربي، 2020). ومن جانب آخر دفعت الأزمة كافة الدول إلى تبني سياسات عاجلة سواء لمواجهة الأزمة الصحية أو لمواجهة تداعياتها الاقتصادية والاجتماعية أو الإثنين معا.

ويعرض الجدول (1) بالملحق نماذج للسياسات التي اتخذتها الدول في مواجهة الأزمة وفقا لما رصده صندوق النقد الدولي. ويتضح من هذا الجدول تتوع السياسات الاقتصادية ما بين سياسات مالية تحفيزية وأخري نقدية توسعية. 2 ضمت السياسات المالية: توسع الإنفاق على الصحة والبحوث الخاصة بالفيروس وشراء مستلزمات الوقاية وتجهيزات المستثفيات، وكذلك تأجيل المدفوعات الضريبية المستحقة على الأفراد والشركات. بينما ضمت السياسات النقدية: تخفيض أسعار الفائدة وضمانات قروض للبنوك وتوسع البنوك المركزية في شراء السندات السيادية. وأخيراً، ضمت السياسات حزم لمساندة القطاعات المتضررة نتيجة الأزمة مثل السياحة وذلك من خلال توفير السيولة لها، وتحمل الدولة للأجور أو لنسبة منها لتحفيز الشركات على الاحتفاظ بالعمالة، وتأجيل الإيجارات ورسوم المرافق للمنازل والشركات الصغيرة، وتقديم إعانات بطالة عاجلة، ودعم مادي مباشر للفئات ذات الاخول المتدنية، ودعم وتيسيرات تمويلية للمنشآت الصغيرة ومتتاهية الصغر •

1ومنها صندوق النقد الدولي ومؤسسة التمويل الدولية والبنك الدولي للإنثاء والتعمير والبنك الإسلامي للتمية ومجموعة العشرين ${ }^{2}$ IMF, IMf policy tracker, 2020 


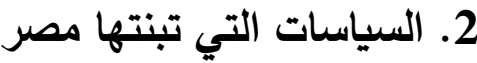

مع بداية ظهور الفيروس وانتشاره في مصر خلال مارس 2020، بادرت الدولة باتباع سياسات استباقية للحد من تراجع معدل النمو الاقتصادي، ولتحفيز النشاط الاقتصادي، وحماية العمالة غير المنتظمة وكلها إجراءات هامة ومطلوبة حتى وإن كان من المبكر رصد أثرها وفعاليتها الآن. وقد ركزت السياسات على جانبين: أولهما زيادة الدعم الموجه لقطاع الصحة للسيطرة على الفيروس، ثانيهما: مساندة القطاعات والفئات المتضررة من الأزمة. وقد تتوعت السياسات التي تبنتها مصر في مواجهة الأزمة ما بين سياسات مالية وأخري نقدية ونعرض فيا يلي هذه السياسات بمزيد من

\section{السياسات النقدية}

مع اتجاه البنوك المركزية على مستوى العالم إلى تخفيض أسعار الفائدة قام البنك المركزي المصري بخفض أسعار الفائدة ب 300 نقطة أساس لتتخفض أسعار الفائدة الخاصة بمعدل العائد على الإيداع والإقراض لليلة واحدة وسعر الأتتمان والخصم إلى 9.25 \%، و 10.25\%، و9.75\% على التوالي (البنك المركزي المصري، 2020). تأجيل سداد أقساط القروض لمدة 6 شهور ، وإسقاط استحقاقات قدرها 10 مليار جنيه للعملاء الأفراد غير المنتظمين. • تأجيل الاستحقاقات الائمانية لعملاء شركات التمويل العقاري والتأجير التمويلي والتخصيم. مبادرة تخفيض الديون للأفراد المقترضين. خفض أسعار الفائدة على المبادرات التي أعلنها البنك المركزي قبل الأزمة إلى 8\% بدلا من 10\% وتضم هذه المبادرات: 100 مليار جنيه لدعم الصناعة والمصانع المتعثرة، و 50 مليار جنيه لاعم التمويل العقاري لمتوسطي الدخل إتاحة 50 مليار جنيها لتمويل الإسكان لمتوسطي الاخل من خلال البنوك. برنامج لإسقاط المديونية على المزارعين وتأجيل سداد القروض إلى سبتمبر 2020. إتاحة 50 مليار تمويل بفائدة 8\% لشركات السياحة وبفترات سماح 6 شهور حتى تتمكن من الوفاء بالتزاماتها أثناء الأزمة. 
للحد من السيولة في المعروض النقدي، تم وضع حد أدني وأقصى لعمليات السحب والإيداع للأفراد مع توسيع قيود التعاملات اليومية للشركات. للحد من الدولرة طرحت البنوك العامة شهادات بعائد 15\% للأفراد.

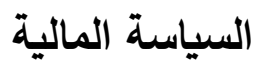

وفقاً لوزارة المالية، تم تخصـيص حزمة تحفيزية بقيمة 100 مليار جنيه لمواجهة الأزمة بما يمثل 1.9 \% من الناتج المحلي الإجمالي للعام المالي 2019/2018 ولتمويل الإجراءات التالية: زيادة مخصصات قطاع الصحة وتحسين دخول العاملين بالمهن الطبية: 1. اعتماد إضافي 4 مليار لوزارة الصحة للتجهيزات ورفع كفاءة المستشفيات بها. 2. 200 مليون جنيه اعتماد إضافي لمشروع الإمداد بالتجهيزات الطبية المتقدمة بخطة وزارة الصحة

3. 2.25 مليار جنيه لتمويل زيادة بدل المهن الطبية بـ 75\%. 4. رفع مكافأة أطباء الامتياز بالمسـتثـفيات الجامعية التابعة لوزارة التعليم العالي والبحث العلمي، ومسـتشـفيات جامعة الأزهر التي تُصـرف حاليًا بما يتراوح بين 400 إلى 700 جنيه، لتصبح 2200 جنيه شهريًا منحة شهرية بقيمة 500 جنيه للعمالة غير المنتظمة لمدة 3 شهور. تأجيل دفع الضرائب العقارية للمصانع والمنشآت السياحية لددة 3 أثهر • • إلغاء رسوم المنظومة الإلكترونية للممولين من الأشخاص الطبيعيين هذا العام. تأجيل سداد الضريبة العقارية المستحقة على المصانع والمنشآت السياحية لمدة 3 أشهره ، والسماح بتقسيط الضريبة العقارية المستحقة على المصانع والمنشآت السياحية عن الفترات السابقة، من خلال أقساط شهرية لمدة 6 أشهر • رفع الحجوزات الإدارية عن كافة الممولين الذين لديهم ضــيبة واجبة الســاد مقابل ســاد 10 من الضربية المستحقة عليهم إعفاء الأجانب من ضرائب الأرباح الرأسمالية وتأجيلها للمقيمين حتى بداية عام 2022. تقســيط ضــريبة الدخل المســحقة عن عام 2019 لكل الثــركات العاملة في القطاعات المتضررة (الطيران، والسياحة، والصناعة، والتصدير) تأجيل الضرائب المستحقة القطاعات المتضررة دون فوائد أو غرامات تأخير . 
مد وقف ضريبة الأطيان الزراعية لمدة عامين.

السياسات القطاعية

ضمت مجموعة من الإجراءات لمساندة القطاعات المتضررة من الأزمة ومساعدتها على الوفاء بالتزاماتها المالية أثناء الأزمة. ويعرض الجدول الجاه التالي أهم هذه الإجراءات.

جدول (2): أهم السياسات القطاعية التي تبنتها مصر لمواجهة الأزمة

\begin{tabular}{|c|c|}
\hline إجراءات المساندة & القطاع \\
\hline 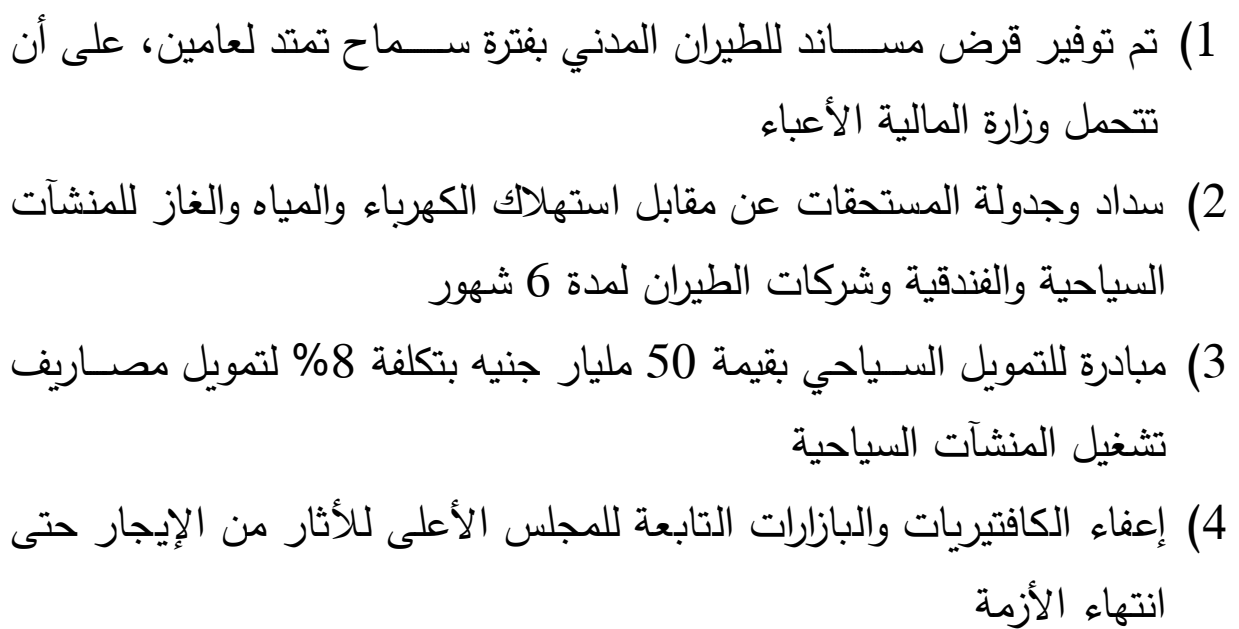 & والسياحة \\
\hline 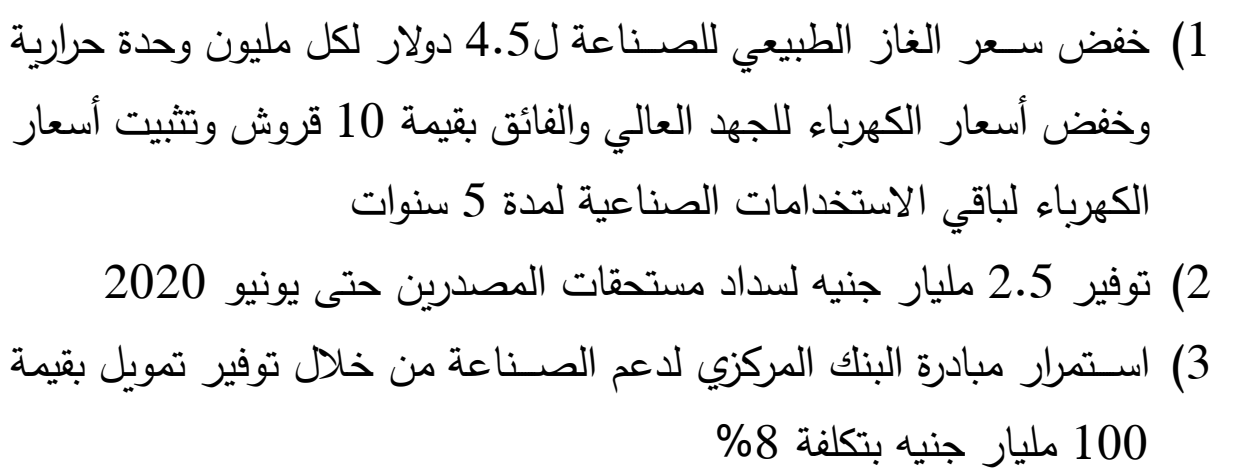 & الصناعة \\
\hline 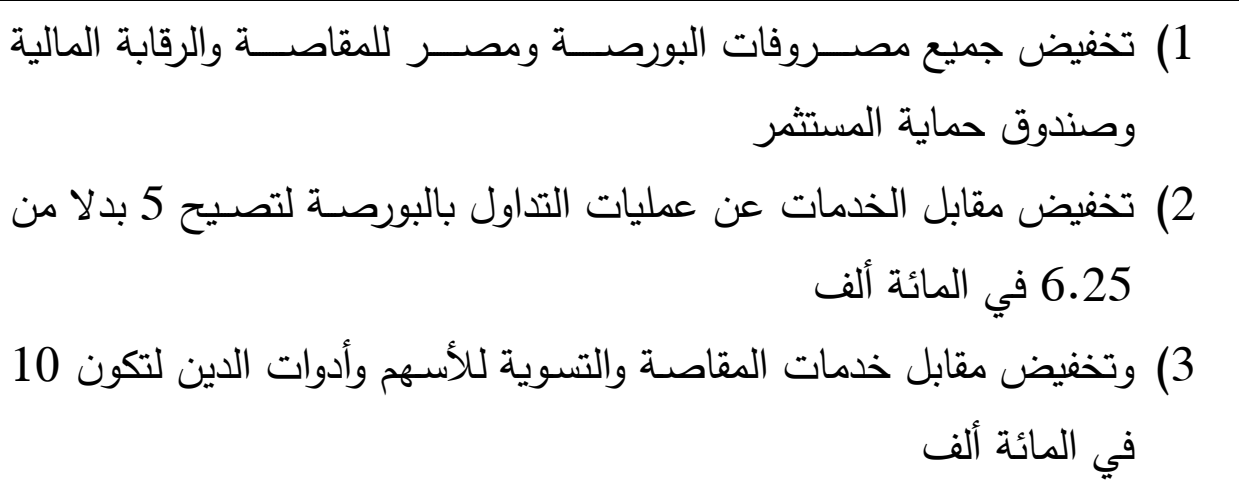 & البورصة \\
\hline
\end{tabular}

المصدر: مصـادر متتوعة ضمت مجلس الوزراء، البنك المركزي المصري، وزارة المالية، وزارة التخطيط، وزارة

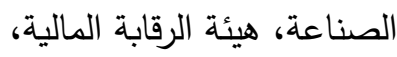


رابعاً: تقدير الأثر المتوقع لأزمة كورونا على النمو الاقتصادي في مصر : مدخل دالة الإنتاج تزخر الأدبيات بالعديد من المناهج والآليات التي يمكن من خلالها تتبع أثر الأزمات على النمو لإسي

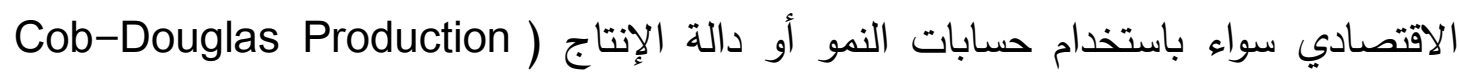
Function مصادر النمو من مقومات مادية وبشرية بالإضافة إلى اعتبارات الكفاءة في إدارة هذه المقومات لتحليل أثر ما تم اتخاذه من سياسات على معدل النمو الاقتصادي وفي ضوء افتراضات محددة.

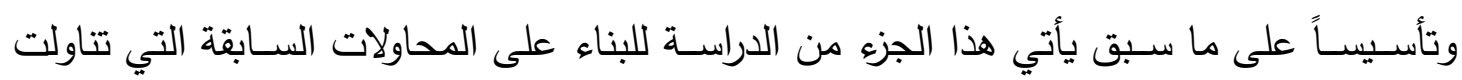
تداعيات أزمة كورونا على النمو الاقتصادي بمصر ، والتي استخدمت منهجيات متباينة ومحددات مختلفة عما اســـخدمته الدراســـة الحالية لتقدير الأثر الأولي المحتمل لأزمة كرونا على النمو الاقتصـــادي في مصــر، حيث تبنت هذه الدراســـة مدخل دالة الإنتاج والتي تأخذ في اعتبارها التفاعل بين محددات الإنتاج الثلاثة وهي العمل ورأس المال وكذللك الإنتاجية الكلية للعوامل، مما يسـح بدراسـة أثر هذه المحددات على النمو الاقتصـادي في ضـوء تداعيات أزمة كرونا. وتجدر الإثـارة إلى أن النموذج المقدم يُعد بمثابة نقطة البداية، والتي يمكن الانطلاق منها والبناء عليها، لوضـع نموذج أوسـع للاقتصـاد يأخذ في اعتباره بجانب العوامل المباشـرة المؤثرة على معدل نمو الناتج المحلي الإجمالي العوامل غير المباشرة أيضاً.

1.قنوات انتقال الأزمات للنمو الاقتصادي وسياسات التعامل: خلفية نظرية تتاولـت العديـد مـن الأدبيـات التـداعيات السلبية للأزمـات علـى النمـو الاقتصـادي، والقــوات

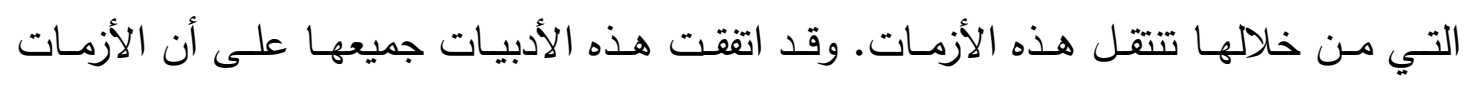

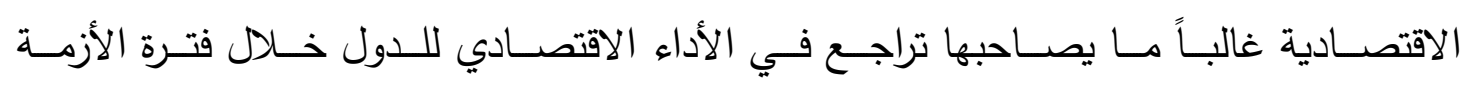
ويستمر مع طول مدتها.

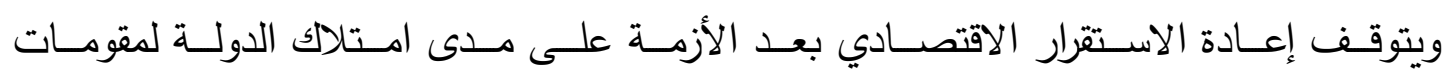

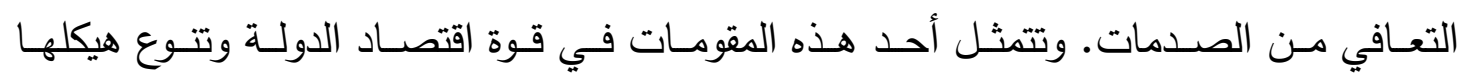

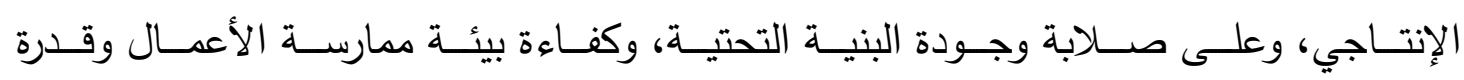

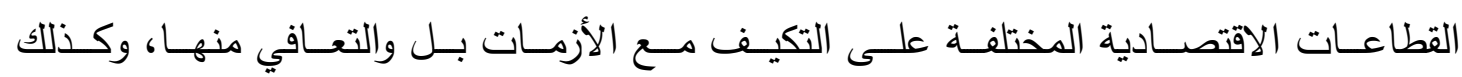

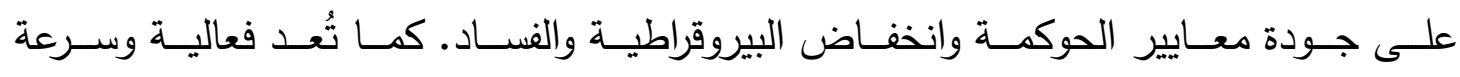

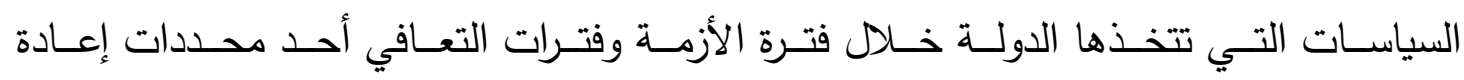




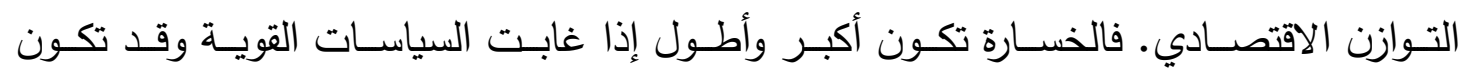
السياسـات القويـة المناسـبة أثتاء الأزمـة سـببا في تحقيق طفرة في حجم ومعدل نمـو النـاتج المحلي بمعدلات قد تقوق مثيلتها قبل الأزمة. ونظرياً، من المهم التأكيد على أن أثار الركود الاقتصادي على مكونات الناتج تختلف عبر المدي الزمني؛ فقد تكون العلاقة بين فترات الركود والنمو المتوقع طويل الأجل سلبية أو إيجابية وفقا للألية التي ينشا النمو من خلالها (European Commission, 2013) وقـــ أظهـرت مراجعـة الأدبيـات الاقتصـادية أن التـــوات الرئيسـية التـي تعبـر مـن خلالهـا

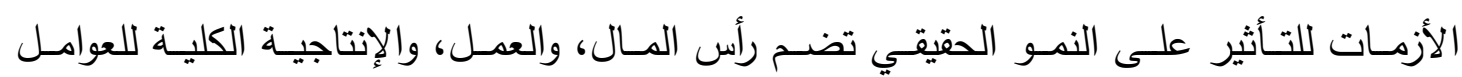
والتـي تمثـل جميعهـا محـددات دالــة الإنتـاج، كمــا طورتهـا نظريـات النمـو بـدءاً مـن آدم

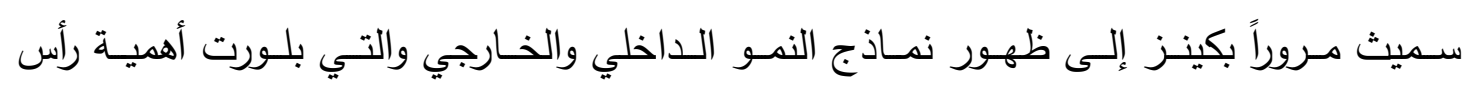
المال البشري بجانب المادي في تحقيق النمو الاقتصادي . 1-1 1 - 1التراكم الرأسمالي: أشـارت الأدبيـات أن الأزمـات الماليـة والاقتصـادية غالبـاً مـا يتبعهـا انخفـاض في معـدل

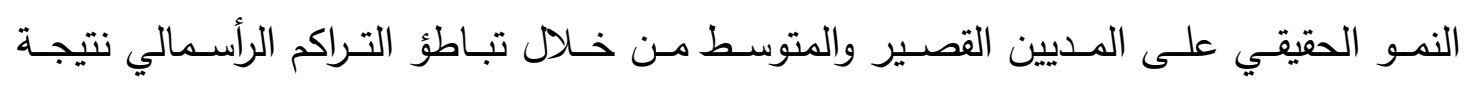

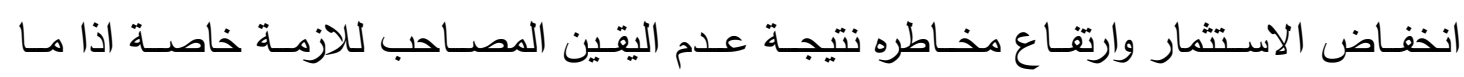

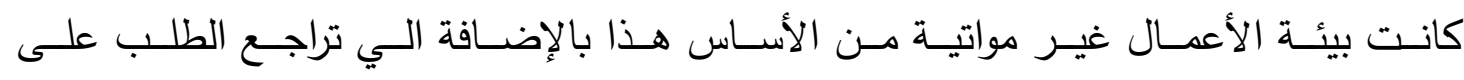

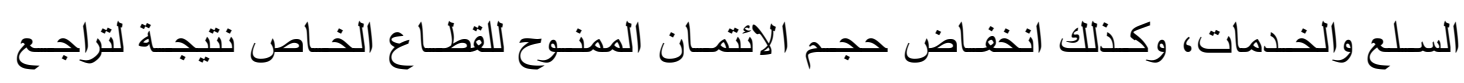

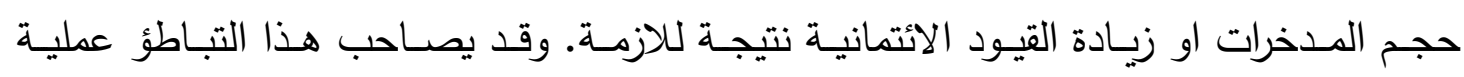
إعادة هيكلة اقتصادية.(Furceri, Mourougane,2009)

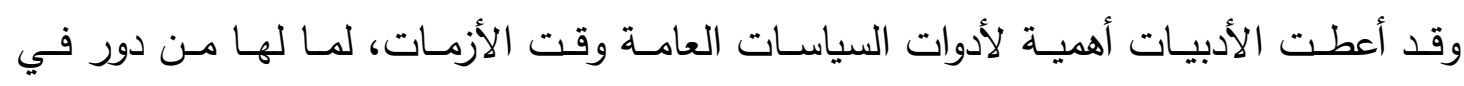

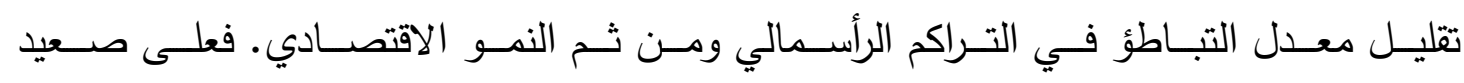

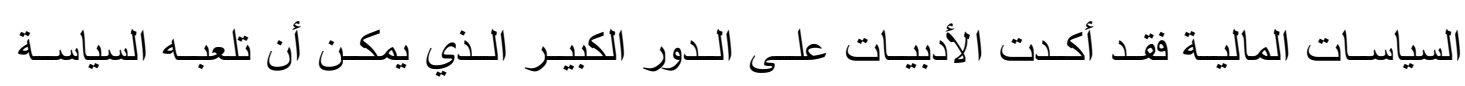

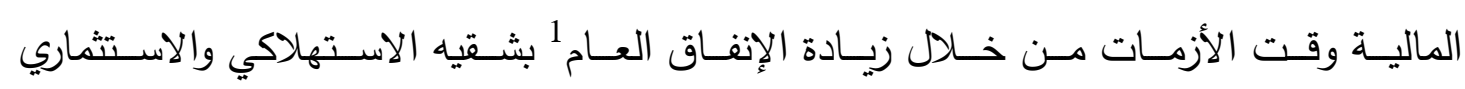

1 تعتبر العلاقة بين الإنفاق العام والنمو الاقتصادي من أحد الموضوعات التي حظيت باهتمام كبير في الأدبيات الاقتصادية بدءاً من

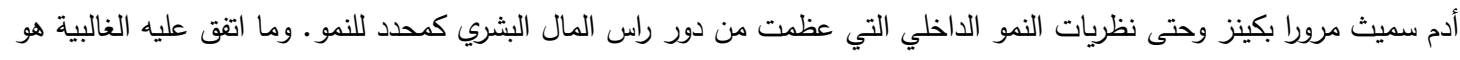

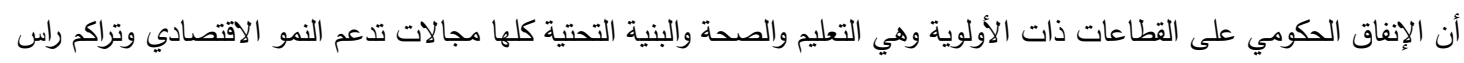


لتعــويض جـزء مــن تراجــع الاســتثمارات الخاصــة، وكــذلك تقــديم الحــوافز والإعفــاءات الضـريبية لتحفيـز القطـاع الخـاص على مواصـلة نشـاطه الإنتـاجي ومزيـــــــن تحسـين بيئة (IMF, 2008). الأعمال

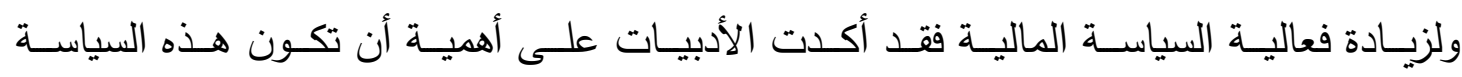
موجهـة لـدعم أنشـطة بعينهـا لهـا الأولويـة وقـت الأزمـات ومـن أهمهـا الأنشــة الإنتاجيـة والأنشـطة كثيفـة العمالـة وغيرهـا، حيث يصـبح مضـاعف الإنفـاق العـام بهذه الحالـة أقصـى (IMF, 2008). ما يمكن مقارنة لو كانت السياسة المالية عامة وغير موجهة وبالرغم من إشارة الأدبيات لأهمية هذه السياسة، إلا أنها اتفقت أن فعالية هذه السياسة تتباين بين الدول، وأنه لا يمكن وضع نموذج واحد يصلح للتطبيق علي جميع الدول، ومن ثم فإنه لابد من توخي الحذر حيث أن الإفراط في استخدام أدوات هذه السياسة قد يؤدي إلي حدوث أزمة كبيرة في الدين العام مستقبلاً والتي بطبعها تكبل معدل النمو المستقبلي وهو ما قد يدخل الدولة في حلقة مفرغة، وتعد هذه المشكلة ذات أولوية كبرى بالنسبة للدول ذات المديونية المرتفعة ومنها مصر .(Furceri, Mourougane,2009) وقـد طرحـت دراسـات أخـري حــولا لهـذه الإشـكالية تتمثـل فـي أنـه لا يشـترط لـدفع النمـو الاقتصــادي أن يـتم زيـادة الإنفــاق العـام فقـــ يكفـي إعـادة توزيعــه لصــالح القطاعـات ذات الأولويـة. ويرجـع ذلـك إلـى أن سـوء تخصسيص المـوارد هـو السـبب وراء تحقيـق معـدل نمـو اقل من المعدل الأمثل خاصة في الدول النامية (Yilmaz,2018) •

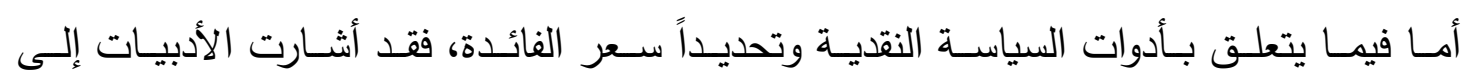
أن هـذه السياسـة يمكـن أن تلعـب دور تحفيـزي وقـت الأزمـات، مسن خـلال تخفـيض سـعر الفائـدة على الاقتـراض ومـن ثـم تحفيـز الاسـتثمارات إلا أنـهـ لا يمكن التعويـل على خفـ سـعر الفائـدة بمفـرده لتحفيـز الاســتثمار خاصــة وقــت الأزمــة وخاصــة إذا كانــت بيئسة الأعمـال غيـر مواتيـة وهنـاك قيـود علـى الائتمـان مـن ناحيـة الثـروط والإجـراءات. لـذا يكـون مـن الأفضـل تخفيض الأعبـاء الماليـة عـن كاهـل الثـركات وقـت الأزمـة حتى تـتكن مـن مواصـلة نشـاطها وتظـل محتفظـة بالعمالـة وكـذلك تيسـيرات اسـتثنائية تـدفع الأنشـطة ذات معـدلات العائد الإيجابيـة وقـت الأزمـة. وفي كل الأحـوال أكدت الأدبيـات على أهميـة

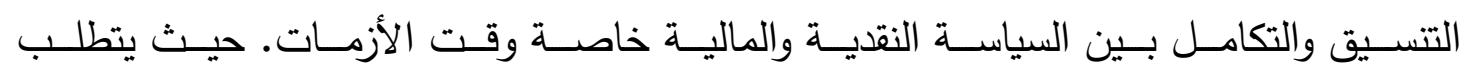


التوسـع المـالي لتحفيـز التبـاطؤ فـي النشـاط الاقتصـادي بعــــالأزمـات اتبـاع سياســة نقديـة انكماشية من خلال رفع أسعار الفائدة) (IMF, 2008)

1-2 قوة العمل

تناولت الأدبيـات الاقتصـادية أهميـة عنصـر العـل في دفع النهـو الاقتصـادي. وقد تتاولت

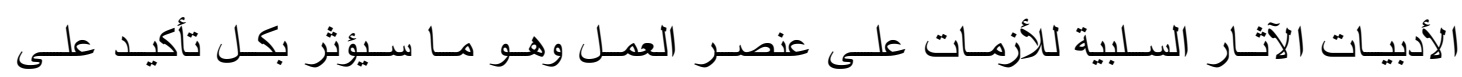
النمـو ومعدلاتـه، وفي هـا الإطـار أثـارت الأدبيـات إلـى أنـهـ بـالرغم مـن أن الأثر النهائي

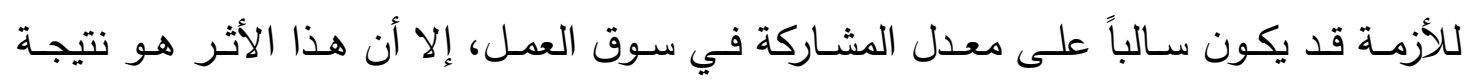
تضـافر أثرين متضـادين. الأثر الأول وهـو (الأثر الموجب)، واللذي يتمثل في سـى أفـراد

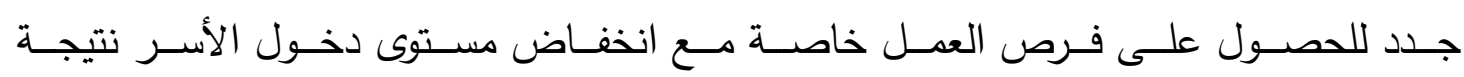
للازمــة (مثل ربـات المنزل). بينمـا الأثر الثاني (الأثر السـبي)، والـذي يتمثل في خـروج

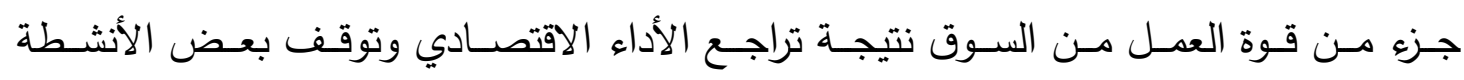
او عودة العاملين بالخارج وبالتالي ارتفاع معدل البطالة نتيجة للازمة.

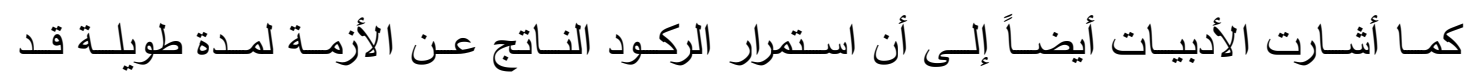

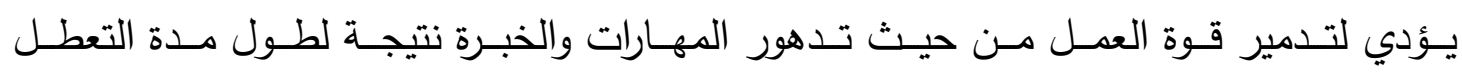
وبالتالي نمو سريع لمعدل تضخم البطالة وبالتالي مزيد من الخسائر علي الناتج المتوقع (Furceri, Mourougane,2009). ووفقـاً للأدبيـات يتوقف الأثر النهائي للأزمـات على عنصـر العمل على توقيـت احتـواء

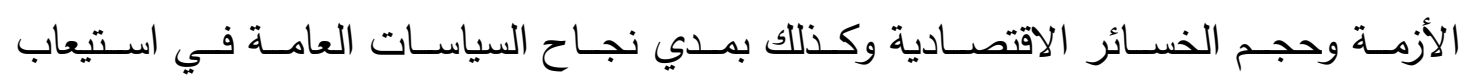
المتعطلين في مرحلتي الأزمة والتعافي بعد الأزمة. 1 3-1 الإنتاجية الكلية للعوامل فيل تعـد الإنتاجيـة الكليـة للعوامـل أحـــ القـــوات التـي تتنقـل عبرهـا الأزمـات للتـأثير على النهـو الاقتصـادي. حيـث تعكس الإنتاجيـة الكليـة مـدى الكفـاءة في اسـتخدام المـوارد الاقتصـادية المتاحة (المادية والبشرية).

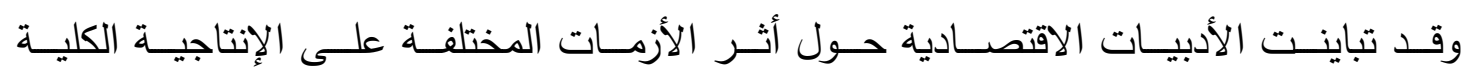

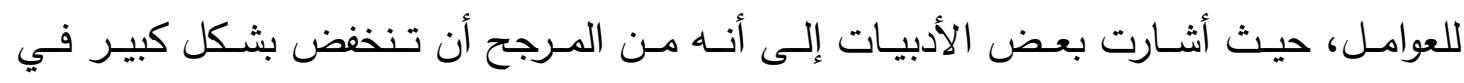

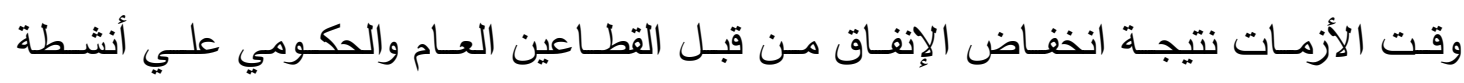


البحث والابتكار و التعليم والمهارات وقت الأزمـة . (Millard, Nicolate,2012).هذا

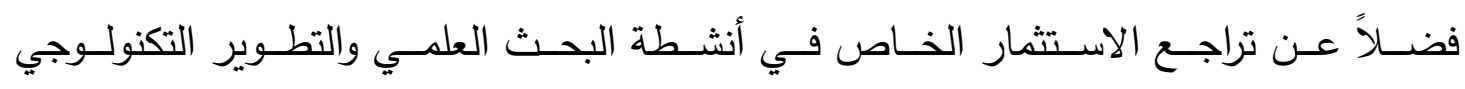

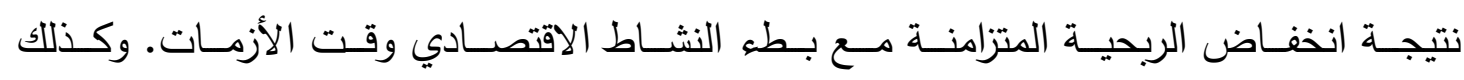

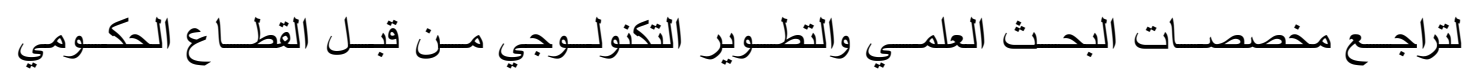

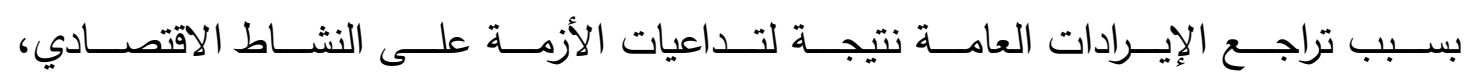
بالإضـافة الـي قيـام الحكومـة بتوجيـه مـا هـو متـاح نحو تحفيـز الطلب الكي للتخفيف مـن (European Commission, 2013). التداعيات الاقتصادية للأزمات وفي مقابـل الاتجـاه السـابق فقــ أشـارت بعض الأدبيـات الأخـرى إلـي أن عوامـل الخطـر

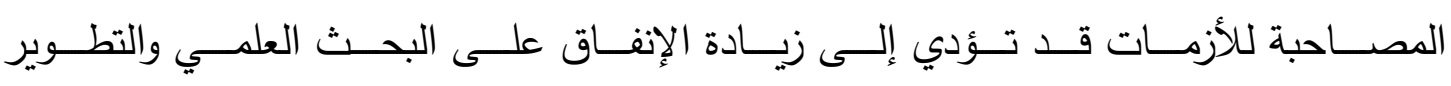

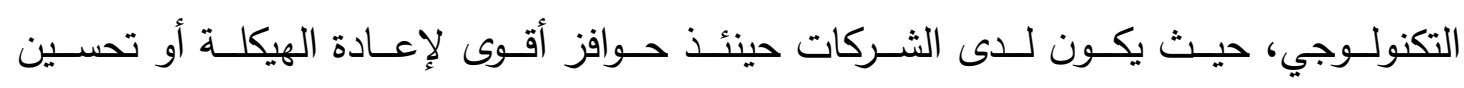
كفاءتها في فترات الأزمات للحد من خسائرهم.(Giebe, Kraft, 2015)

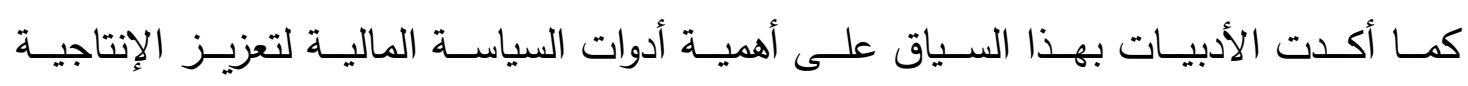

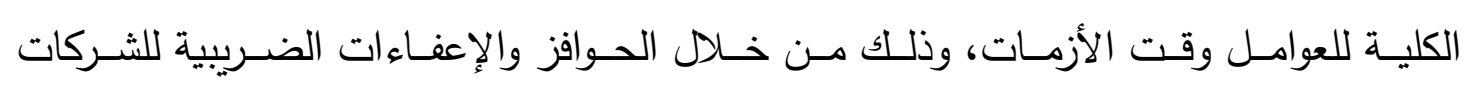

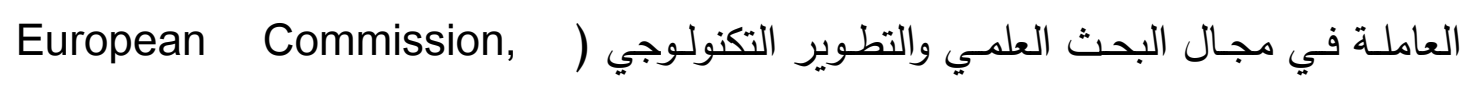

\section{افتراضات النموذج}

يرتبط التعرف على تبعات الأزمة بمدي اليقين وحداثة البيانات المتاحة وبما أن الأزمة الحالية

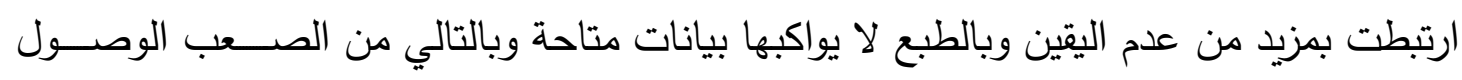
لتقديرات دقيقة. لذا سيتم الاسترشاد بأزمتين للوصول إلى افتراضـات موضوعية وذلك للمتغيرات

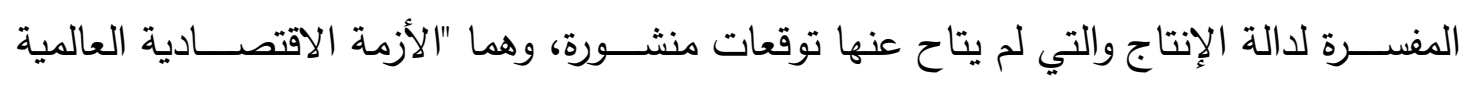

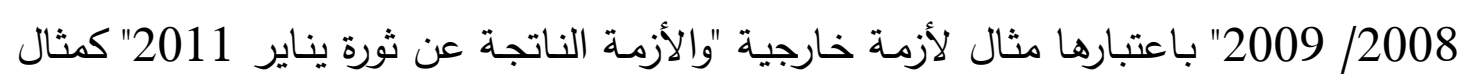

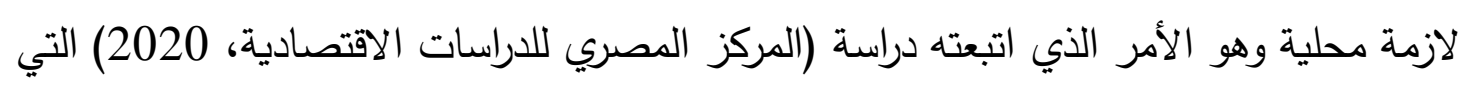
اعتمدت على أثر الأزمتين في مصسادر نمو الناتج لتقدير معدلات النمو المتوقعة خلال المراحل الزمنية للازمة. يضـاف إلى ذلك اسـتعانة الدراســة بما تم اتخاذه من سـياسـات خلال الأزمة وتحديدا قيام البنك المركزي بتخفيض سعر الفائدة ب 300 نقطة أسـاس في مارس 2020، وكذلك مستهدفات وزارة 
التخطيط والتتمية الاقتصادية حول التقديرات المتوقعة للاستثمارات العامة والخاصة بمصر خلال

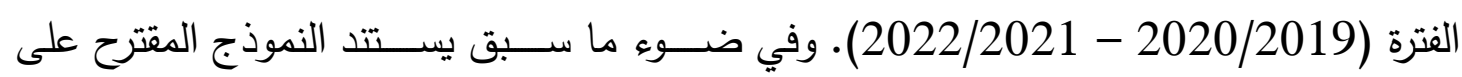
مجموعة الافتراضات التالية:

- السيطرة علي الفيروس بنهاية يونيو 2020 وبداية التعافي اعتبارا من يناير 2021 - زيادة معدل نمو الاستثمارات العامة من أجل تحفيز النشـاط الاقتصـادي خلال الأزمة، ثم ثباتها مع إعادة هيكلتها وذلك بتوجيه مزيد من الاستثمارات لقطاع الصـحة وكذللك لتعويض الانخفاض في الاستثمارات الخاصة خلال الأزمة. - تراجع الاســتثمارات الخاصـــة نتيجة عدم اليقين بثـــأن الأزمة وتبعاتها ونتيجة لتراجع الطلب

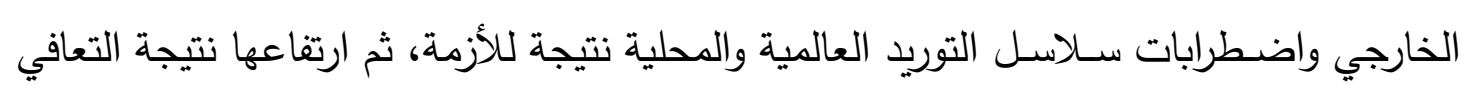
من تبعات الأزمة.

- اتباع سـياسـة نقدية توسـعية، وذلك بتخفيض سـعر الإقراض بهدف تتشـيط الاقتصـاد المحلي

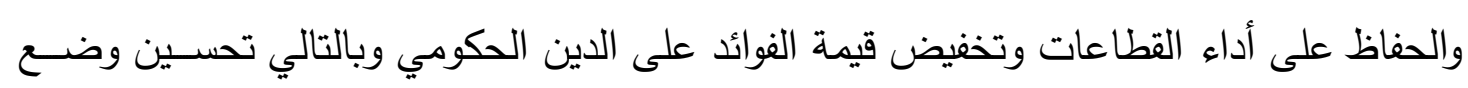
الموازنة العامة للدولة. - تحرك طفيف لسعر الصرف خاصة وأن الأزمة فرضت ضغوطا كبيرة على مصادر النقد الأجنبي

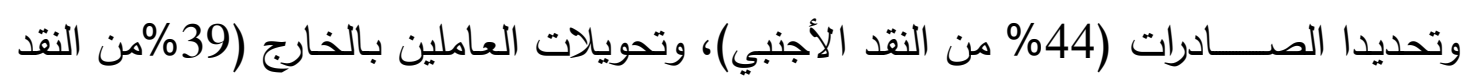

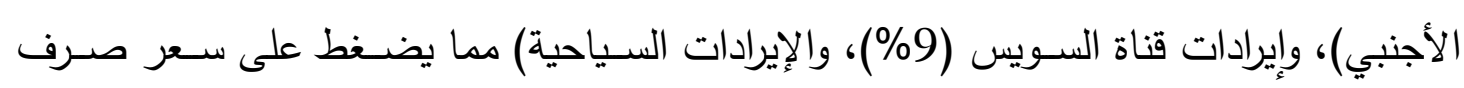

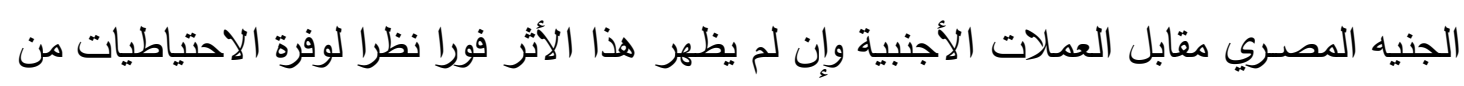

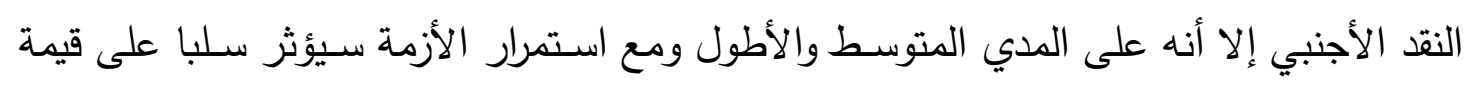
الجنيه المصري. - ارتفاع طفيف في معدل التضـــم نتيجة لتداعيات الأزمة على ســلاســل التوريد محليا وعالميا بالإضــافة إلى تقليص ســـاعات الإنتاج وســـوء منظومة التجارة الداخلية وارتفاع تكاليف النقل والخدمات اللوجيستية.

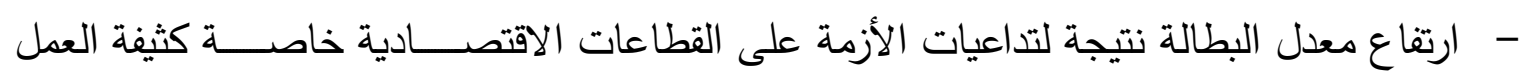

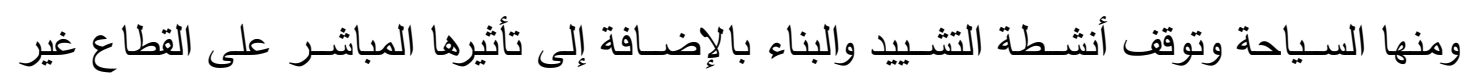
الرسـمي الذي يمتص عدد كبير من العمالة علاوة على عودة غالبية المصـرين العاملين بالخارج 
- - تراجع طفيف في معدل نمو الإنتاجية الكلية للعوامل، وذللك نتيجة تراجع مخصــصــات الانفاق على البحث العلمي والتطوير التكنولوجي. جدول (3): افتراضات النموذج

\begin{tabular}{|c|c|c|c|c|c|c|}
\hline البطالة معدل & الاستثمارات & الاستثمارات & التضخم & الصرف & سعر & 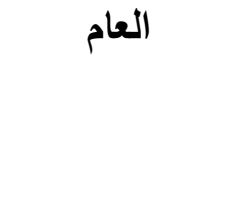 \\
\hline 11.00 & $-37 \%$ & $17 \%$ & $\% 9.2$ & 16.78 & 10.25 & $2019 / 2020$ \\
\hline 13.00 & $-53 \%$ & $11 \%$ & $\% 10.12$ & 17.68 & 10.25 & $2020 / 2021$ \\
\hline 10.50 & $33 \%$ & $0 \%$ & $\% 9.8$ & 16.77 & 10.25 & $2021 / 2022$ \\
\hline
\end{tabular}

توصيف النموذج المقترح

تفترض دالة الإنتاج أن الناتج المحلي الإجمالي الحقيقي يتم توليده في ضوء ثلاثة عناصر رئيسية وهي عنصر العمل، وعنصر رأس المال، وعنصر الإنتاجية الكلية للعوامل ( Total Factor (Productivity $Y_{t}=K^{V *} L^{1-V} * T F P_{t}$

بحيث $Y_{t}$ تشير إلى الناتج المحلي الإجمالى في الزمن t؛ وتشير TFP إلى الإنتاجية الكلية للعوامل في الزمن t؛ بينما تشير V و - 1 و إلى إنتاجية رأس المال والعمل على التوالي، كما

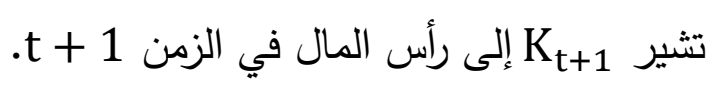
System Dynamics ) وقد اعتمدت الدراسة في هذا الإطار على منهجية ديناميكيات النظم Methodology)، وتستخدم هذه المنهجية في صياغة النماذج التي تحتوى على عدد من النماذج Qi-) الفرعية، والتي تتكون من مجموعة من المتغيرات تتفاعل مع بعضها البعض بشكل متزامن Fan,etal, 2005 ). وتتميز منهجية ديناميكات النظم عن منهجيات الاقتصاد القياسي في العديد من النقاط لعل أهمها يقع في عدم وجود قيود على عدد المتغيرات المفسرة في النموذج، حيث لا تتطلب هذه المنهجية ربط عدد المتغيرات المفسرة في النموذج بعدد المشاهدات في السلاسل الزمنية محل الدراسة، كما تتمايز هذه المنهجية في تتاولها لأثر التغذية العكسية بين المتغيرات المفسرة في النموذج· وقد اشتملت الفترة الزمنية للنموذج المقدر الفترة (2008/2007 - 2019/2018) 
وفي ضوء دالة كوب دوجلاس للإنتاج وفي إطار منهجية ديناميكيات النظم يتكون النموذج العام بالدراسة من متغيرات رئيسية مترابطة معاً في نموذج عام أكبر ، وهي رأس المال، والعمل والإنتاجية الكلية للعوامل. كما يتحدد كل متغير من عدد من المتغيرات والمعلمات الفرعية، وذلك على النحو في الشكل التالي.

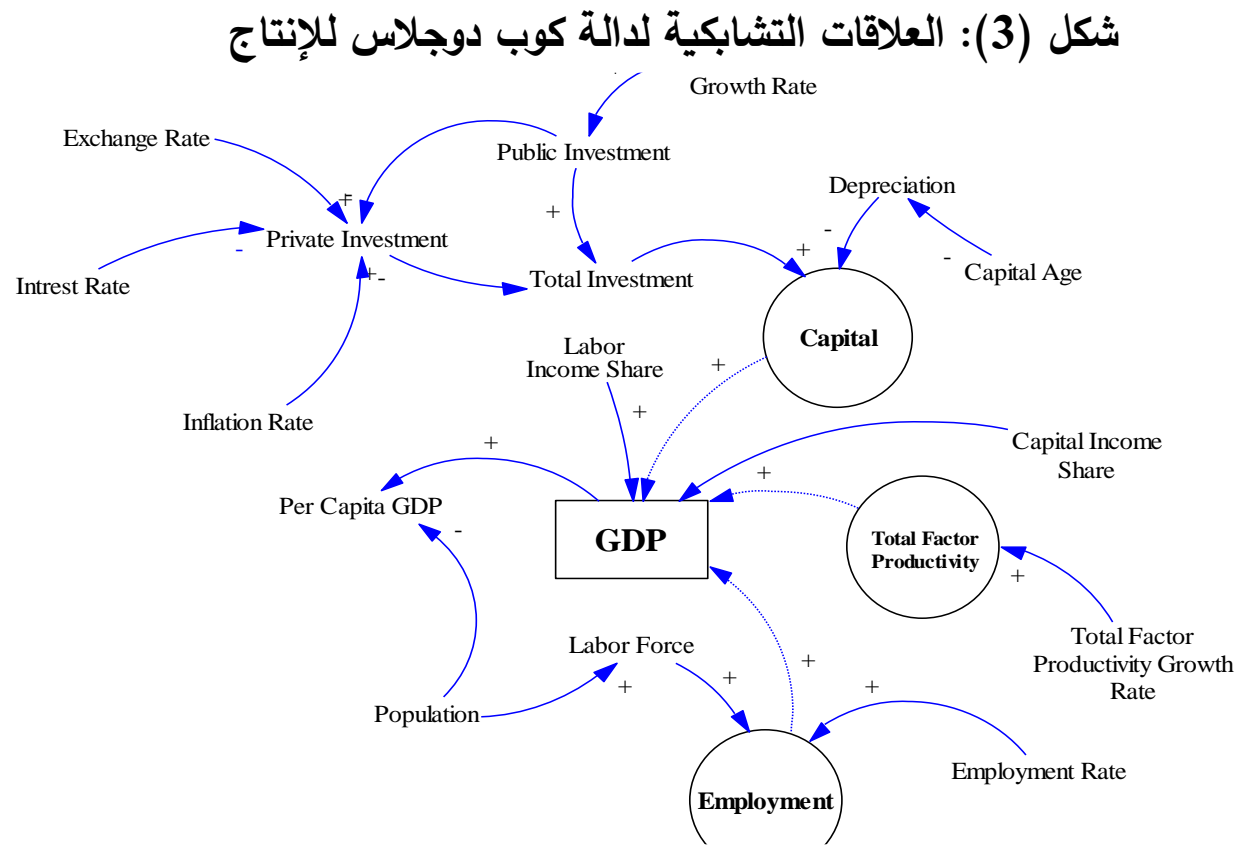

ويوضح الجدول رقم (2) بملحق الدراسة العلاقات التي تربط بين المتغيرات والمعلمات المتضمنة في الشكل السابق. Capital أ) رأس المال في ضوء عدم توافر بيانات سنوية عن قيمة رأس المال بمصر ، فقد اعتمدت الدراسة على تقديرات لرأس المال في دراسات سابقة (Ibrahim,2019) ومن ثم تم تقدير قيمة رأس المال سنوياً في ضوء ما يتم اضافته سنوياً من استثمارات واستبعاد قيمة اهلاك رأس المال كما يلي: اهلاك رأس المال: والذي يؤدي إلى تناقص القيمة المتراكمة لرأس المال المادي سنوياً. وتتوقف القيمة السنوية لإهلاك رأس المال على عمر الأصول الإنتاجية، والذي قُدرت قيمته وفقاً لنموذج المحاكاة بهذه الدراسة بنحو 20 عاماً لمصر • الاستثمارات المحلية (الاستثمار الخاص والعام)، والتي تئدي إلى زيادة القيمة المتراكمة لرأس المال سنوياً. 
بالنسبة للاستثمار العام، فقد اعتمدت الدراسة على بيانات الاستثمار الفعلية خلال فترة الدراسة والتي تصدرها وزارة التخطيط والتتمية الاقتصادية، حيث أن الاستثمار العام يتحدد في ضوء قرارات اقتصادية للدولة في ضوء الموارد المالية المتاحة وأهداف خطة التنمية المستدامة لمصر . بالنسبة للاستثمار الخاص: تجدر الإشارة إلى عدم وجود تقديرات دقيقة للاستثمار الخاص في مصر ، حتى ما تقوم بنشره وزارة التخطيط كقيم للاستثمار الخاص هي في الواقع قيم تقديرية. وفي ضوء عدم وجود بديل أكثر دقة حتى الآن لهذه التقديرات فإن الدراسة استخدمت التقديرات المتاحة من قبل وزارة التخطيط مع التحفظ عليها وذللك للفت صانع القرار لأهمية تطوير منهجية علمية دقيقة لقياس الاستثمار الخاص في مصر • وفي ضوء وجود العديد من المحددات التي تلعب دوراً في تحديد حجم الاستثمار الخاص في مصر وفقاً للنظرية الاقتصادية والدراسات التطبيقية، فقد اعتمدت الدراسة لاختبار وتقدير العلاقة التوازنية طويلة الأجل بين الاستثمار الخاص ومحدداته Engle Granger Cointegration ) على منهجية التكامل المشترك لإنجل وجرانجر (Approach الأجل بين الاستثمار الخاص ومحدداته على النحو المبين في المعادلة التالية ((معادلة رقم 1)):

\section{$\log (P R I N V)=4-0.04 \log (I R)+0.3 \log (I F R)+0.9 \log (E R)+0.5$}

\section{$\log (G D P)$}

حيث تشير (Log(PRIN) إلى لوغاريتم الاستثمار الخاص، كما تشير (IR(IR) إلى لوغاريتم سعر الإقراض، وتشير (IOgR(IFR) إلى لوغاريتم معدل التضخم، كما يشير إلى (IogR) لوغاريتم سعر الصرف، بينما يشير إلى (log(GDP) لوغاريتم الناتج المحلي الإجمالي. وقد أظهرت نتائج التقدير عن وجود تأثير سلبي لسعر الاقراض على الاستثمارات الخاصة بمصر، حيث أن زيادة السعر ب 1\% يؤدي إلى زيادة تكلفة الاستثمارات ومن ثم خفض قيمتها المتوقعة

$$
\text { بنحو 0.04\% }
$$

وبالمثل فإن معدل التضخم ب 1\% يؤدي إلى تراجع الاستثمارات الخاصة بنحو 0.3\%، حيث يصاحب ارتفاع معدلات التضخم تتاقص في القوة الشرائية للمستهلكين، وارتفاع أسعار مستلزمات

1 لمزيد من التنصيلات حول محددات الاستثار الخاص وفقاً للنظرية الاقتصادية والدراسات التطبيقية أنظر في ذللك إلى:

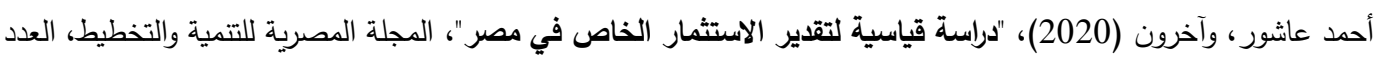
الأول، المجلد 28، معهد التخطيط القومي. 
الإنتاج، وكذللك تراجع في قيمة الأصول الحقيقية للاستثمارات، مما يؤثر بالسلب على حجم الاستثمارات الخاصة.

وبخلاف ما سبق فقد جاءت نتائج التقدير لتشير إلى وجود أثر إيجابي لسعر صرف الجنيه المصري أمام الدولار ونمو الاستثمارات الخاصة، حيث بلغت مرونة الاستثمار لتغيرات سعر صرف الجنيه

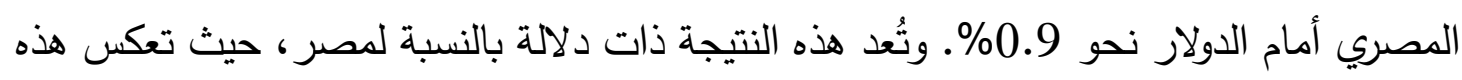
الإثارة اتجاه الدولة للإصلاح الاقتصادي وتحرير سعر الصرف مما انعكس ايجابياً على توقعات المستثمرين حول مزيد من الإصلاحات إلى جانب زيادة تنافسية المنتجات المصرية وتحفيز الاستثمار وخاصة الأجنبي بغرض التصدير والاستفادة من مزايا الاتفاقيات التجارية لمصر مع هع

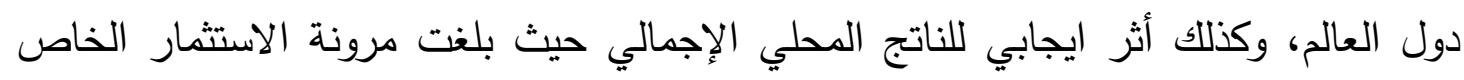

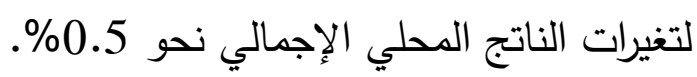
وإذ أن المحددات السابقة تمثل العوامل المؤثرة على حوافز الاستثمار الخاص بمصر في ظل الظروف الطبيعية، والتي حتمياً ستختلف عن العوامل المؤثرة عليه وقت الأزمات، فقد تضمن التحليل أيضاً عنصر مخاطر الاستثمار الناتج عن عدم اليقين المصاحب للأزمة وعدم التأكد بشأن مزيد من تحسينات بيئة ممارسة الإعمال، والذي بالطبع سيؤدي إلى تراجع قيمة الاستثمارات الخاصة المتوقعة بصر في ظل أزمة كرونا وذللك وفقاً للمعدلات السابق ذكرها في جدول (3). Labor 2 عنصر العمل تم قياس متغير العمل في النموذج من خلال نسبة الشتغلين من قوة العمل، وتم الحصول على بيانات المشتغلين وقوة العمل خلال فترة الدراسة من بيانات مسح القوى العاملة التي يصدرها الجهاز المركزي للتعبئة العامة والإحصاء.

3) الإنتاجية الكلية للعوامل Total Factor Productivity أما فيما يتعلق بالإنتاجية الكلية للعوامل فقد تم تقديرها على أساس أنها الجزء المكمل لمساهمة عنصري رأس المال والعمل بمصر في الناتج المحلي الإجمالي الحقيقي (Solow Residual) وفيما يتعلق بمعدل نمو الإنتاجية الكلية للعوامل بمصر، فقد أشارت نتائج (Shahin,2019)

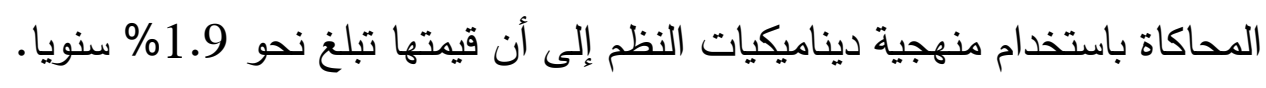


نتائج التقدير في ضوء السياسات التي تبنتها الحكومة لمواجهة تداعيات فيروس كورونا على الاقتصاد المصري، وفي ضوء افتراضات النموذج من المتوقع أن يتراجع معدل نمو الناتج المحلي الإجمالي ليصل إلى نحو 3.9\% خلال عام 2020/2019، ثم إلى نحو 2.6\% خلال عام 2021/2020، ثم يأخذ في التعافي التدريجي ليسجل نحو 2.9\% خلال عام 2022/2021. وبمقارنة نتائج النموذج مع سيناريوهات وزارة التخطيط والتنمية الاقتصادية وسيناريوهات صندوق النقد الدولي، يتضح اتساق نتائج النموذج المقدر مع هذه السيناريوهات وهو ما يُدلل على إمكانية استخدام هذا النموذج لدراسة أثر السياسات على مكونات عناصر الإنتاج الثلاثة ومن ثم على النمو الكلي. خامساً: السياسات المقترحة لافع النمو الاقتصادي في مصر اشتركت كافة التقديرات الخاصة بتأثير الأزمة على النمو على حتميه انخفاض النمو وإن اختلف حجم الانخفاض وتفاوت توقيت التعافي وفقاً لمدى التشاؤم والتفاؤل حول توقيت احتواء الأزمة والسيطرة على الفيروس. وانطلاقاً من الدور المحوري الذي تلعبه السياسات ليس فقط في تحديد الأثر الصافي لهذه الأزمة على الاقتصاد المصري بكافة متغيراته ومن أهمها النمو وإنما في قدرته على التعافي والانطلاق بعد الأزمة. يكون من المهم إيجاد آلية لمتابعة انعكاسات السياسات الحكومية التي تم اتخاذها على مختلف الفئات المستهدفة بثكل مستمر حتى يمكن مراجعتها في ضوء المستجدات وتحسينها بما يزيد من كفاءتها ويتطلب ذلك تواصل مع المستهدفين بشكل مباشر. وفيما يلي مجموعة من التّخلات المطلوبة والتي يمكن من خلالها دفع مصادر النمو ومسانده قطاعاته المحركة وتم تقسيمها إلى تلخلات لها أولوية أثناء الأزمة وأخرى تدخلات بعد الأزمة وهي على النحو التالي: التدخلات التي لها أولوية أثناء الأزمة: الحفاظ على مصادر النمو وقطاعات الاقتصاد القومي 1. حشــد الجهود والموارد للسـيطرة على الفيروس ودعم القطاع الصــحي وتلبية مسـتلزماته

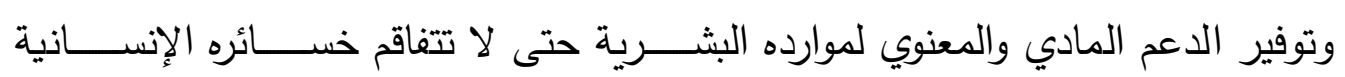
والاقتصادية. 
2. دعم ومسـاندة القطاع الخاص الذي يسـاهم بنحو 70\% من الناتج و 77\% من التشـغيل خاصة الإنتاجي منه حتى يتمكن من الاستمرار والاحتفاظ بالعمالة من خلال:

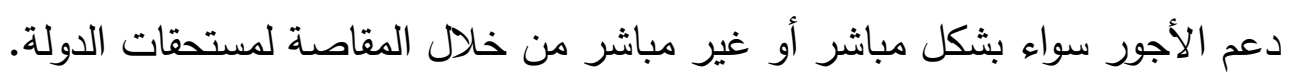
مزيد من الإعفاءات المالية مثل إعفاء جميع الثــركات لمدة محددة من ضـريبة كسـبـ العمل والتأمينات الاجتماعية، وإعفاء المصانع من قيمة الرسوم المفروضة على الطرق، وتأجيل مدفوعات الكهرباء والمياه والغاز ، والإســراع في عملية إصـــدار التصــاريح والتراخيص وتخصـيص الأراضـي للنشـاط الصـناعي. (اتحاد الصـناعات المصـرية، (2020

$$
\text { استمرار توفير التيسيرات التمويلية حتى تتنهي الأزمة }
$$

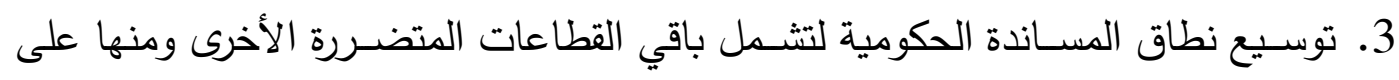

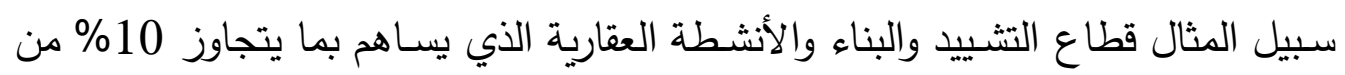
الناتج و 15\% من التثـــيل، وذلك نظرا لما يواجهه القطاع من توقف نشــــاطه نتيجة

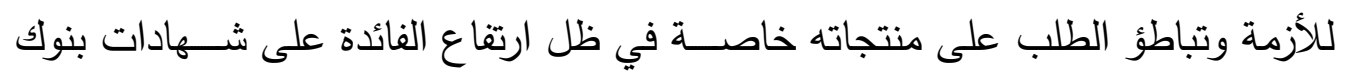
القطاع العام. وقد يتضمن ذلك سرعة صرف دفعة من مستحقات المقاولين حتى يتمكنوا من الاســمرار وصـندوق للطوارئ للعاملين يمكن من خلاله تحمل تكلفة إجازات العمالة في حالة الإصابة. (American Chamber of Commerce in Egypt,2020) 4. مسـاندة موجهة للمنشـآت الصـغيرة والمتوسطة التي تمثل ما يزيد عن 90\% من إجمالي

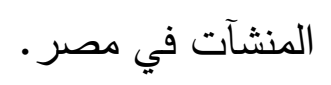

5. حزم سـياسـات لدعم قطاع الاتصـالات وتكنولوجيا المعلومات باعتباره محركا للنمو وآلية لتحقيق التحول الرقمي خاصة وأنه أثبت الدور الدحوري الذي يلعبه الآن في خدمة العديد من القطاعات ومنها العمل، والتعليم والخدمات المالية، والبنوك، والخدمات الحكومية.

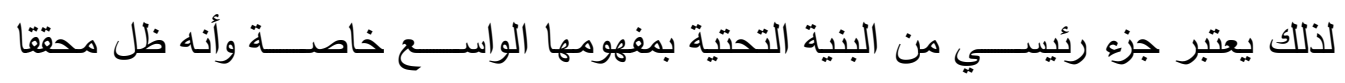
لمعدلات نمو مرتفعة أثناء الأزمتين السابقتين ومعدل نمو أكبر خلال الأزمة الحالية .

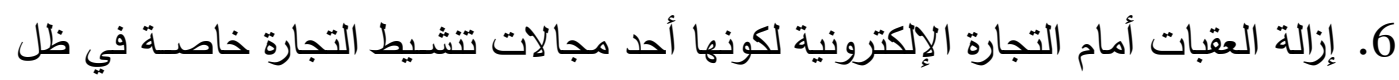
الإجراءات الاحترازية وتباطؤ الطلب. 
7. ضمان الحد الأدنى من الدخل للفئات التالية:

- المتضــررين من الأزمة من خلال اســتمرار تقديم منحة العمالة غير المنتظمة طالما الأزمة مستمرة - الفقراء ويمثلوا نحو 32.5 \% من إجمالي السكان 1 وذلك من خلال استمرار برامج الدعم

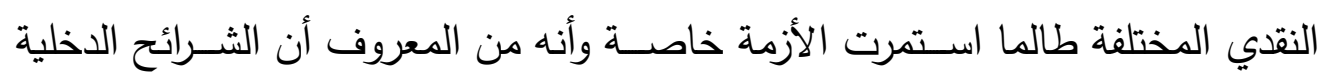
الدنيا ميلها الاستهلاكي أعلي.

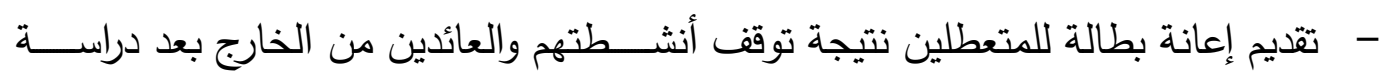

$$
\text { أوضاعهم المعيشية. }
$$

وهنا تجدر الإثارة إلى أن الإجراءات السابقة تتطلب تفعيل المشاركة الحقيقية ما بين الدولة

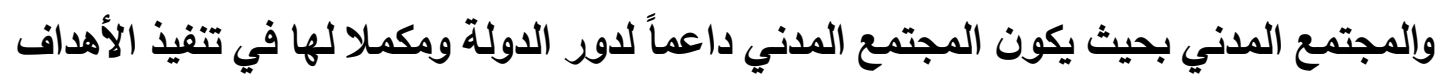

ويضاف إلى ما سبق ضرورة تدبير موارد إضافية لتمويل الإنفاق العام المتزايد في ظل الأزمة ويمكن أن يكون ذللك من خلال ما يلي على سبيل المثال: دراسة إمكانية الاستفادة من آليات التمويل السريع للطوارئ والتي تتيحها المنظمات الدولية لأعضائها ومنها صندوق النقد الدولي لمواجهة الظروف الاستثنائية التي فرضتها الأزمة مع ضرورة التأكيد على الثفافية في إدارتها وتوجيهـا للقطاعات الأكثر احتياجا في هذه الأزمة وهي القطاعات الإنتاجية والقطاعات المحركة للنمو ، والصحة والتعليم.

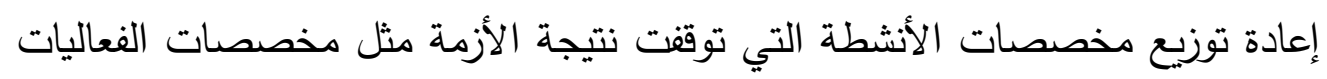
الرياضية لوزارة الثباب والرياضة، ومخصصات الإنتاج الفني وزارة الإعلام، ومخصصات

$$
\text { الآثار والسياحة، وغيرها. }
$$

إعادة النظر في توزيع النفقات العامة للدولة، وتحديداً الباب السادس في الموازنة العامة

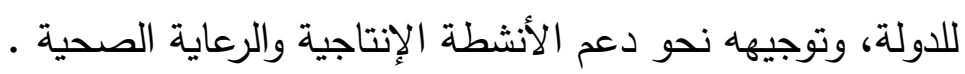




\section{• التدخلات بعد الأزمة فيقترح التركيز على ما يلي:}

1. إطار واضح ومستقر للسياسات الاقتصادية الكلية بأهداف استراتيجية تدفع محفزات الإنتاجية الكلية وتخدم عليها كافة السياسات المالية والنقدية والقطاعية وقاعدة بيانات

$$
\text { محدثة دوريا ومتاحة عن كافة المتغيرات. }
$$

2. التعجيل بإطلاق استراتيجية الإحلال محل الواردات مع ضرورة أن يتم تحديد المنتجات التي يمكن إنتاجها محليا بدقة وبناء على دراسة جدوى اقتصادية سليمة بمشاركة كافة

$$
\text { الأطراف المعنية. }
$$

3. مزيد من الجهود لتحفيز الاستثمارات المحلية والأجنبية وذلك من خلال:

-توضيح حدود دور الدولة في النشاط الاقتصادي وهو أمر ينعكس على ثقة المستثرين المحليين والأجانب ودافعيتهم لاتخاذ قرار الاستثار .

- إصلاحات عاجلة لمعوقات بيئة الأعمال (الإجراءات- التراخيص-الضرائب -

$$
\text { 4. مراجعة الإنفاق الحكومي بشقيه الجاري والاستثماري }
$$

على مستوى الخطة الاستثمارية للدولة:

- - يتم توجيهها نحو الأنشطة الإنتاجية مثل الصناعة والزراعة بدلا من تركزها في

$$
\text { الأنشطة الاستخراجية والأنشطة العقارية }
$$

- زيادة نصيب قطاع الاتصالات وتكنولوجيا المعلومات باعتباره محركا رئيسيا للنمو - يكون لقطاع الصحة مخصصات تسمح برفع كفاءته على مستوى مخصصات النفقات بالموازنة العامة للدولة: - مراجعة مخصصات الإنفاق العام على الصحة والتعليم والبحث العلمي بحيث يكون لهما الأولوية في الإنفاق العام باعتبارهم أهم محددات النمو الاقتصادي في الأجل الطويل.

5. منظومة صحية تضمن حصول الجميع على الخدمات الصحية الأساسية بأعلى جودة وبأقل تكلفة خاصة للفئات الفقيرة والتي تمثل نحو 32.5 \% من إجمالي السكان وفقا لمسح الدخل والإنفاق لعام 2019. 
6. منظومة حماية اجتماعية للعمالة غير المنظمة والعاملين بالقطاع غير الرسمي تكفل لهم

$$
\text { الحياة الكريمة خاصة في أوقات الأزمات. }
$$

7. مراجعة قوانين العمل وما يرتبط به من قوانين التأمين الصحي والاجتماعي لتضمين

الأنماط الجديدة وتحديدا فيما يتعلق بالعمل عن بعد وما يرتبط بذلك من حقوق وواجبات

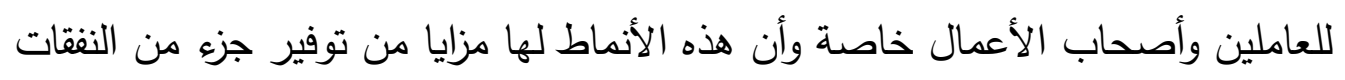
الرأسمالية وكذلك النفقات التشغيلية التي تعد جزء من الأعباء المالية للمؤسسات.

خاتمة خلصت الورقة إلى أن الأزمة الحالية قد تؤدي إلى تداعيات تفوق في شدتها أي أزمات سابقة مرت

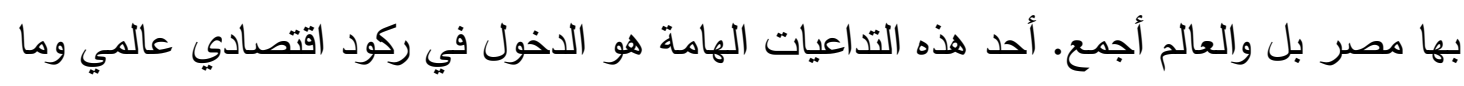
يتبع ذلك من تراجع في معدل النمو الاقتصادي العالمي ولكافة الأقاليم. وقد أثرت الأزمة سلباً على العديد من المتغيرات وقطاعات الاقتصاد المصري سواء نتيجة تأثر العالم بالفيروس وتراجع معدلات الطلب والاستثمار واضطرابات سلاسل التوريد أو توقف الأنشطة الاقتصادية وانخفاض معدل التجارة الدولية نتيجة الإجراءات الاحترازية لمواجهة الفيروس. يلي ذلك التأثيرات الناتجة عن تأثر مصر بالفيروس وتوقف جزء من الأنشطة الاقتصادية نتيجة للإجراءات الاحترازية لمواجهة الفيروس.

وفي هذا السياق بادرت الدولة باتباع سياسات للحد من تراجع معدل النمو الاقتصادي، ولتحفيز النشاط الاقتصادي، وحماية العمالة غير المنتظمة وكلها إجراءات هامة ومطلوبة إلا أنه من المبكر لراع دراسة أثرها وفعاليتها، ولكن من المتوقع في ظل ارتفاع عدم اليقين المصاحب للأزمة وارتفاع سعر الفائدة حتي بعد تخفيضه أن يكون تأثير السياسة النقدية محدود خاصة على الاستثمار الخاص وبالتالي يظل المجال مفتوحاً أمام دور أكبر للسياسة المالية من خلال الاستثمارات العامة إلا أن تضخم حجم الدين الإجمالي سيظل مكبلا لها وبالتالي يكون لإعادة تخصيص الموارد الدور الأكبر في هذه الأزمة بالإضافة إلي الاستفادة من التيسيرات المالية المتاحة من المؤسسات الدولية لمواجهة الطوارئ. في ضوء السياسات التي تبنتها الحكومة لمواجهة تداعيات فيروس كورونا على الاقتصاد المصري، وفي ضوء افتراضات نموذج الدراسة فمن المتوقع أن يتراجع معدل نمو الناتج المحلي الإجمالي 
ليصل إلى نحو 3.9\% خلال عام 2020/2019، ثم إلى نحو 2.6\% خلال عام 2021/2020، ثم يأخذ في التعافي التدريجي ليسجل نحو 2.9\% خلال عام 2022/2021. ولمواجهة التباطؤ المتوقع لأزمة كورونا على النمو الاقتصادي كما أظهرته نتائج الدراسة قدمت

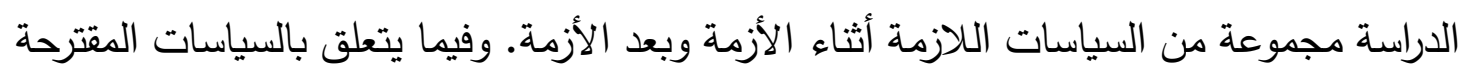
أثناء الأزمة فقد اشتملت على السيطرة على الفيروس من خلال دعم القطاع الصحي وتلبية مستلزماته وتوفير الدعم المادي والمعنوي لموارده البشرية. واستمرار توفير الدد الأدنى من الدخل للفئات المتضررة من الأزمة ومنها العمالة غير المنتظمة وأخيراً، مساندة مستمرة للقطاعات المتضررة حتى تتعافى من خلال توفير مزيد من التيسيرات المالية التي تضمن توافر السيولة وقدرتها على تحمل مصاريف التشغيل. وفيما يتعلق بسياسات ما بعد الأزمة فقد خلصت الدراسة إلى أن الأزمة تُعد بمثابة فرصة لإعادة

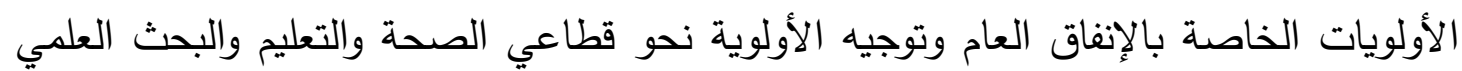
والابتكار باعتبارهم الأساس لتحقيق أي تتمية منشودة وأهم محفزات النمو في الأجل الطويل. كما تعد الأزمة فرصه أيضا للتعجيل بإطلاق استراتيجية الاحلال محل الواردات وكذلك لتتفيذ الاستراتيجية القومية للتحول الرقمي إلا أن الأمر يتطلب تبني سياسات تستهف دعم قطاع الاتصالات وتكنولوجيا المعلومات باعتباره محركاً للنمو خاصة وأنه أثبت الدور المحوري الذي لإني يلعبه الآن في خدمة العديد من القطاعات ومنها العمل والتعليم والبنوك والخدمات الحكومية. 


\section{المراجع}

أولاً: المراجع باللغة العربية

- ـ اتحاد الصــناعات المصـرية، (2020)، ورقة اتحاد الصــناعات المصـرية بثـأن الإجراءات العاجلة

لمواجهة تداعيات فيروس كورونا على المستوى الاقتصادي والصناعة المصرية".

- البنك المركزي المصري، بيانات لجنة السياسة النقدية خلال شهري مارس وابريل 2020 ـ

- - البنك المركزي المصري(2020)، "النشرة الاقتصادية الثهرية"، مارس.

- صندوق النقد العربي، (2020)،" التداعيات الاقتصـادية لفيروس كورونا المستجد على الدول العربية"،

ابريل

- ـ المركز المصري للدراسات الاقتصادية (2020)، " راي في ازمة: قطاع السياحة في مصر"، العدد 3،

مارس.

- المركز المصــري للدراســات الاقتصــادية (2020)، " راي في أزمة: قطاع الاتصــالات وتكنولوجيا

المعلومات في مصر"، العدد 8، أبريل.

- المركز المصــري للدراسـات الاقتصـادية، (2020)،" التأثير المتوقع لوباء كوفيد 19 على نمو الناتج

المحلي الاجمالي"، راي في ازمة العدد 2.

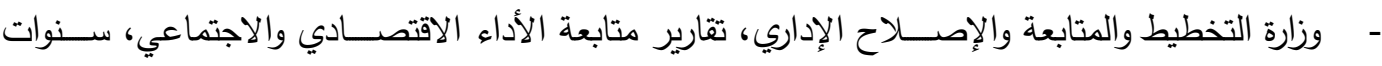

مختلفة.

- وزارة التخطيط والتتمية الاقتصـادية، (2020) " تداعيات فيروس COVID 19 " على الاقتصـاد العالمي

والاقتصاد المصري: السيناريوهات المحتملة واليات المواجهة"، ابريل 2020.

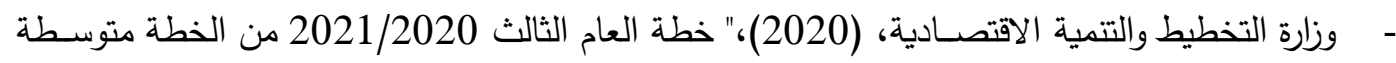

المدي 2019/18- 2022/21"، مايو •

وزارة المالية، (2020)، البيان التمهيدي ما قبل الموازنة للعام المالي 2020/ 2021: موازنة مســاندة

للنشاط الاقتصادي والتتمية البشرية والاصلاح الهيكلي، أبريل.

ثانياً: المراجع باللغة الأجنبية

- Asian Development Bank(ADB),(2020),"The Economic Impact of the COVID-19 Outbreak on Developing Asia", March.

- American Chamber of Commerce in Egypt,(2020)," Impacts of COVID-19 Pandemic on Egypt's Economy “, Research note, March.

- European Commission, 2013, "Impact of the Crisis on Research and Innovation Policies": Study for the European Commission DG Research, Directorate C-Research and Innovation under the framework contract.

- Furceri.D, and Mourougane.A, 2009, "The Effect of Crises on Potential Output: New Empirical Evidence from OECD Countries, Economic Department Working Papers No. 699.

- International Food Policy Research Institute (IFPRI),(2020), COVID-19 and the Egyptian economy :Estimating the impacts of expected reductions in tourism, Suez Canal revenues, and remittances”, Regional Policy Note 04, March. 
- International Labor Organization,( 2020)," COVID-19 and the world of work: Impact and policy responses",ILO.

- IMF, 2008, "Fiscal policy for the Crisis, Fiscal affair and research Department", IMF.

- International Monetary fund (IMF) ,(2020)," Global Economic Outlook: the Great lockdown", April, 2020.

- Ibrahim. M. A. (2010), "Employment and Unemployment in Egypt: a System Dynamics Approach", Thesis Submitted in Partial Fulfilment of the Requirements for the Degree of Master of Philosophy in System Dynamics, Department of Geography.

- Mckinsey\& Company (2020)," Covid-19 : Implications for business: Implications for business", March.

- Millard S. and Nicolae A., (2010), "The effect of the Financial Crisis on TFP Growth: A General Equilibrium Approach", Bank of England.

- OECD,2009, Measuring Capital, OECD.

- OECD Interim Economic Assessment, (2020),"Coronavirus: The world economy at risk", OECD,March.

- Qi-Fan,W.,Xiao-,N. and Jiong,Y. (2005), "Advantages of System Dynamics Approach in Managing Project Risk Dynamics", Journal of Fudan University (Natural Science), 44 (2).

- Shahin.H, 2010, "Estimation of Egypt's Potential Output and Output Gap, Presented in 6th Eurostat Colloquium on Modern Tools for Business Cycle Analysis: the lessons from global economic crisis".

- Surico,P and Andrea ,G. (2020)," The Economics of a Pandemic: The Case of COVID19", London Business school.

- United Nations Conference for trade and Development(UNCTAD), (2020)," Impact of coronavirus outbreak on global FDI flows in 2020-2021", March

- Yilmaz,G.(2018)," Composition of Public Investment and Economic Growth : Evidence from Turkish provinces 1975- 2001", Institute of Public Finance, Public Sector Economics Vol.42,2 PP.187-214.

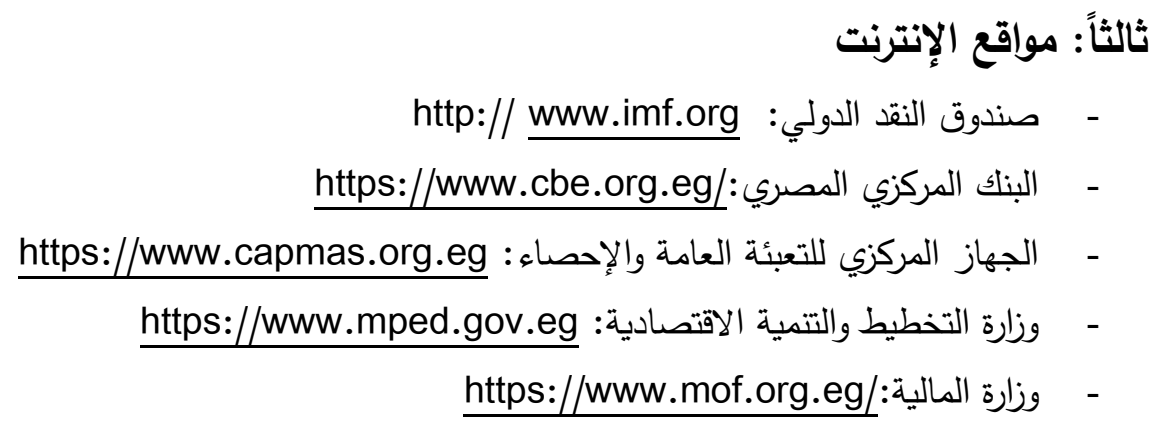




\section{ملحق الدراسة}

جدول (1): بعض نماذج السياسات الاقتصادية التي اتخذتها الدول في مواجهة أزمة كورونا

\begin{tabular}{|c|c|c|}
\hline السياسات النقدية & السياسات المالية الماتية & 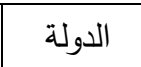 \\
\hline تم تخفيض ســعر الفائدة الفيدرالية بمقدار 150 نقطة & تخصـــيص حوالي 2.3 تريليون دولار أمريكي & 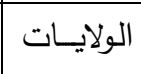 \\
\hline أساس في مارس إلى 0-0.25 نقطة أساس . & (11\% من النـاتج المحلي الإجمـالي) لمواجهـة & المتحــدة \\
\hline -شـــراء ســــدات الخزينة والوكالة بالمبلغ المطلوب. & الازمة وتوزع على النحو التالي: & 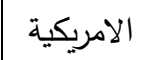 \\
\hline خفض تكلفــة الإقراض. خفض التكلفــة الحــاليـة & 250 مليار دولار أمريكي لتوفير خصـومات & \\
\hline للمبـادلات مع البنوك المركزيـة الرئيســــــة وتمــيـد & 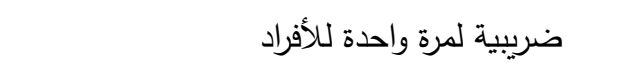 & \\
\hline اســـققاق عمليات الفوركس؛ توسـيع خطوط مقايضــة & - - 250 مليار دولار أمريكي لتوســيع إعانات & \\
\hline الدولار الأمريكي التثــــل المزيد من البنوك المركزية؛ & 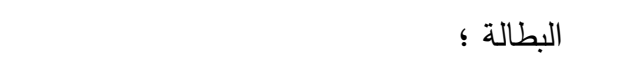 & \\
\hline عرض تسهيلات إعادة الشراء المؤقتة للسلطات النقدية & - 24 مليار دولار أمريكي لتوفير شـــبكة أمان & \\
\hline 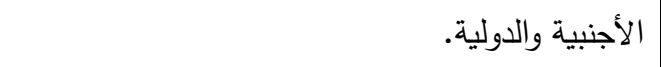 & غذائي لأكثر الفئات ضعفاً ؛ & \\
\hline قدم الاحتياطي الفيدرالي أيضًَــا تســعيلات لدعم تدفق & - 510 مليـار دولار أمريكي لمنع إفلاس & \\
\hline 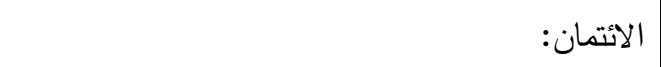 & الشركات من خلال تقديم القروض والضمانات & \\
\hline - تسهيلات تمويل الأوراق التجارية لتسـيل إصدار & ودعم برنامج الاحتياطي الفيدرالي & \\
\hline الأوراق التجارية من قبل الثـركات ومصدري البلديات & - - 359 مليار دولار أمريكي في شـــل قروض & \\
\hline - - تسهيلات ائتمان التاجر الأساسي لتوفير التمويل لـ & وضمانات إدارة الأعمال التجارية الصغيرة & \\
\hline 24 من المتعاملين الأسـاسيين الفيدراليين المضمونين & - 100 مليار دولار أمريكي للمستشفيات ، و & \\
\hline بدجموعـة واســــــة من الأوراق الدـاليـة من الدرجـة & - 150 مليــار دولار أمريكي للتحويلات إلى & \\
\hline 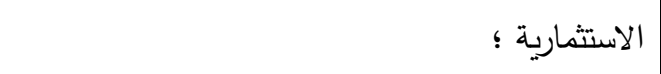 & حكومات الولايات والحكومات الدحلية ، & \\
\hline -سـيولة الصــناديق المشـتركة لســوق المال لتقديم & - - 49.9 مليار دولار أمريكي للمســـاعدة الدولية & \\
\hline القروض إلى مؤسـســات الإيداع لثـراء الأصــول من & (بما في ذلك 28 مليار وحدة ســـب خاصــة & \\
\hline صناديق أسواق النقد الرئيسية & للترتيـب الجـديــ لصـــــدوق النقـــ الـدولي & \\
\hline - التســيلات الائتمانية للشـركات في السـوق الأولية & للاقتراض). ل & \\
\hline لشراء سندات وقروض جديدة من الشركات؛ & - 1.2 مليار لمساعدة المتضررين من الأزمة & \\
\hline - التســيلات الائتمانية للشـركات في السـوق الثانوية & - 8.3 مليار دولار أمريكي للتأهب والاسـتجابة & \\
\hline لتوفير السيولة لسندات الثركات المستحقة؛ & التكميلية لقانون المخصصات التكميلية & \\
\hline -تسهيلات قرض الأوراق المالية المدعومة بالأصول & - 192 مليار دولار أمريكي يمثلون حوالي 1 \% & \\
\hline لأجل إصــدار أوراق مالية مدعومة بأصــول مدعومة & من الناتج المحلي الإجمالي ومخصصة إلى : & \\
\hline بقروض الطلاب وقروض السـيارات وقروض بطاقات & (1) اختبـار الفيروســـــات؛ التحويلات للـدول & \\
\hline الائتــان والقروض التي تضـــمنهـا إدارة الأعمــال & لتمويـل Medical-aid ؛ تطوير اللقــاحــات & \\
\hline الصغيرة وبعض الأصول الأخرى ؛ & والعلاجات والتشخيص ؛ دعم مراكز السيطرة على & \\
\hline - توفير السيولة لبرنامج حماية الرواتب لتوفير السيولة & الأمراض والوقاية منها . & \\
\hline للمؤسسـات المالية التي تتشأ القروض بموجب برنامج & (2) إجازة مرضية مدفوعة لمدة أسبوعين ؛ إجازة & \\
\hline حماية الرواتب في إدارة الأعمال الصـغيرة الذي يوفر & طوارئ لمدة تصل إلى 3 أشـهر للمصـابين (بأجر & \\
\hline حافزًا مباشــرًا للشـركات الصــيرة لإبقاء عمالها على & 3/2) ؛ المســــاعدة الغذائيـة ؛ التحويلات إلى & \\
\hline جدول الرواتب ؛ & الولايات لتمويل التأمين ضد البطالة الموسع . & \\
\hline
\end{tabular}




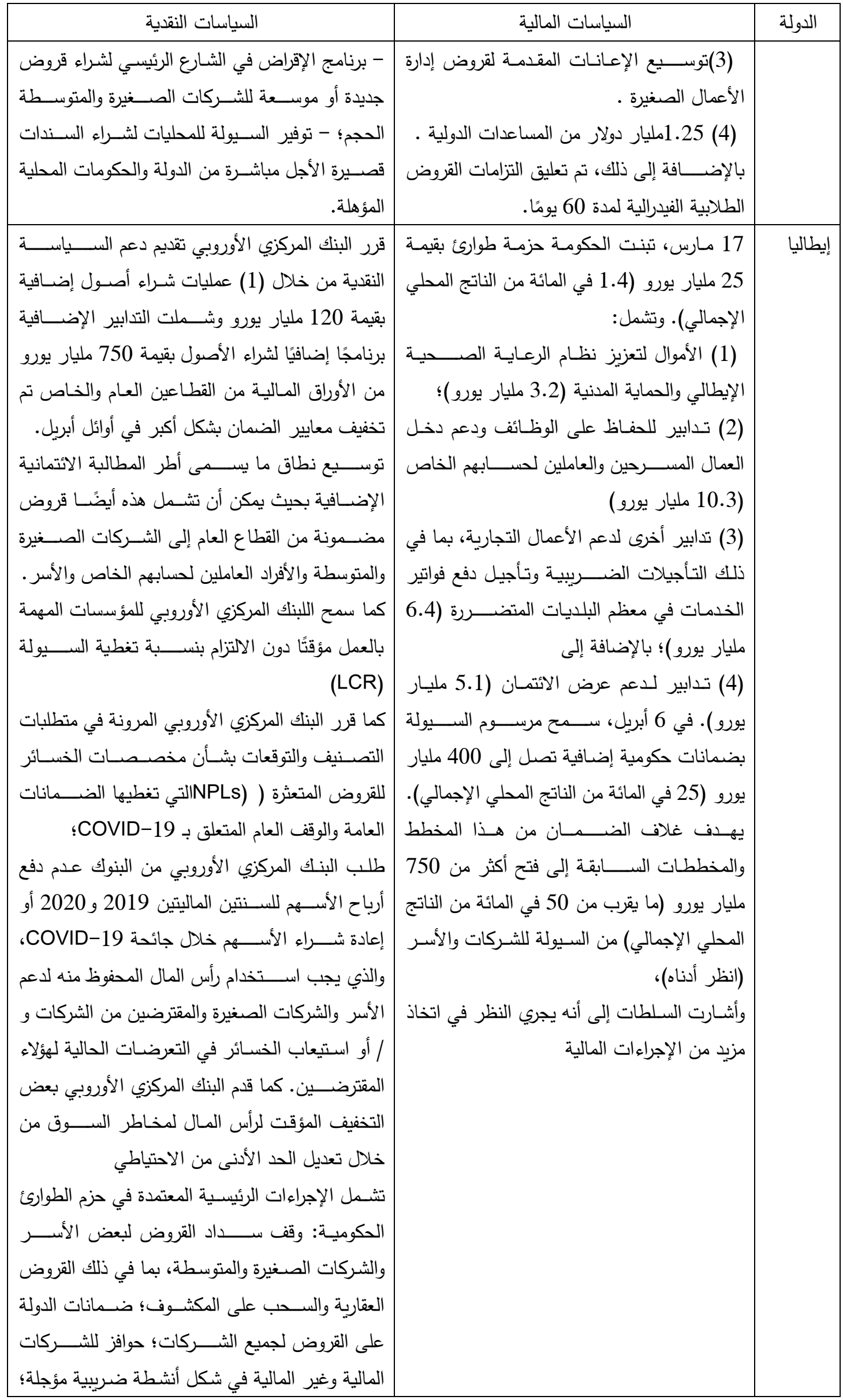




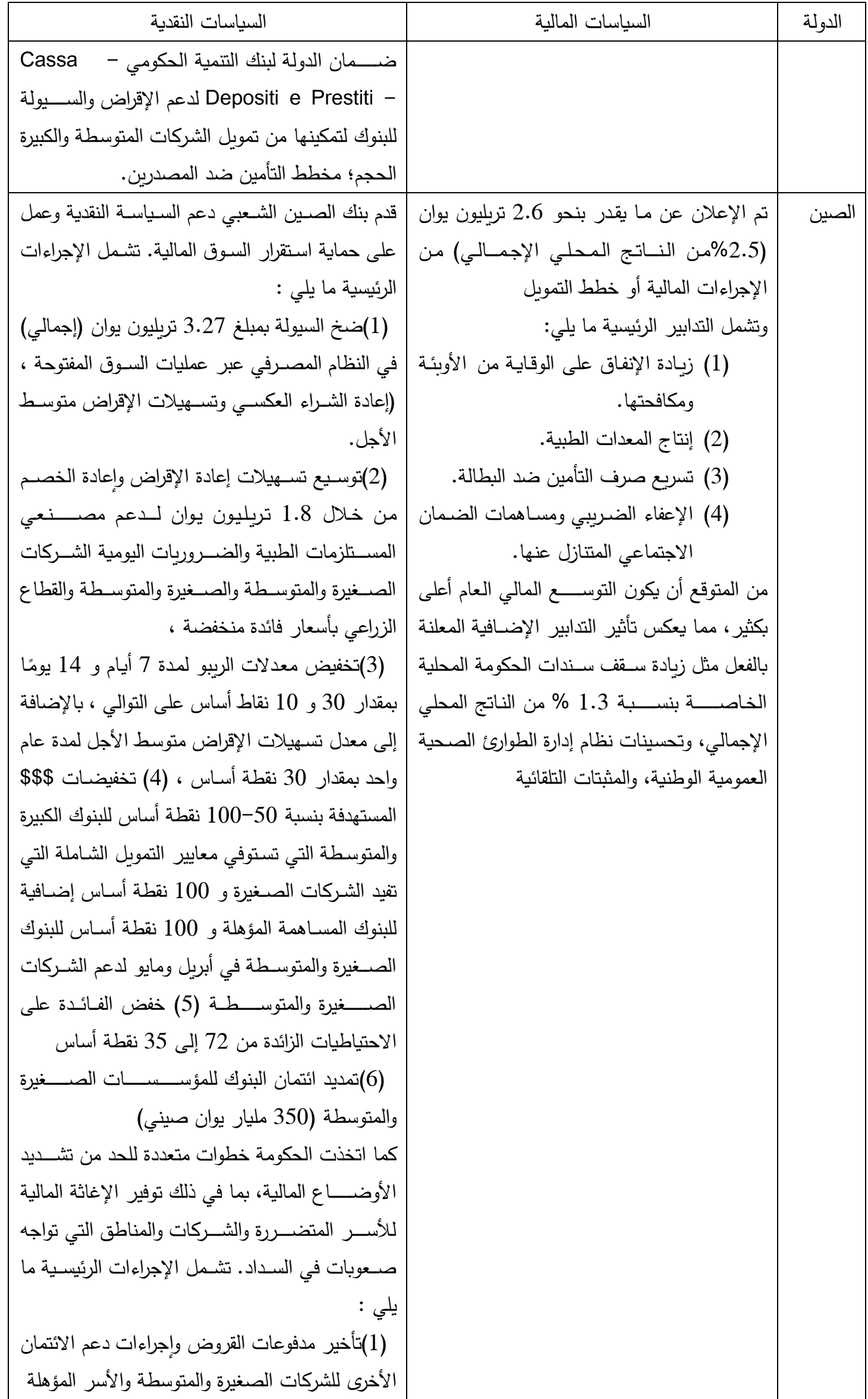




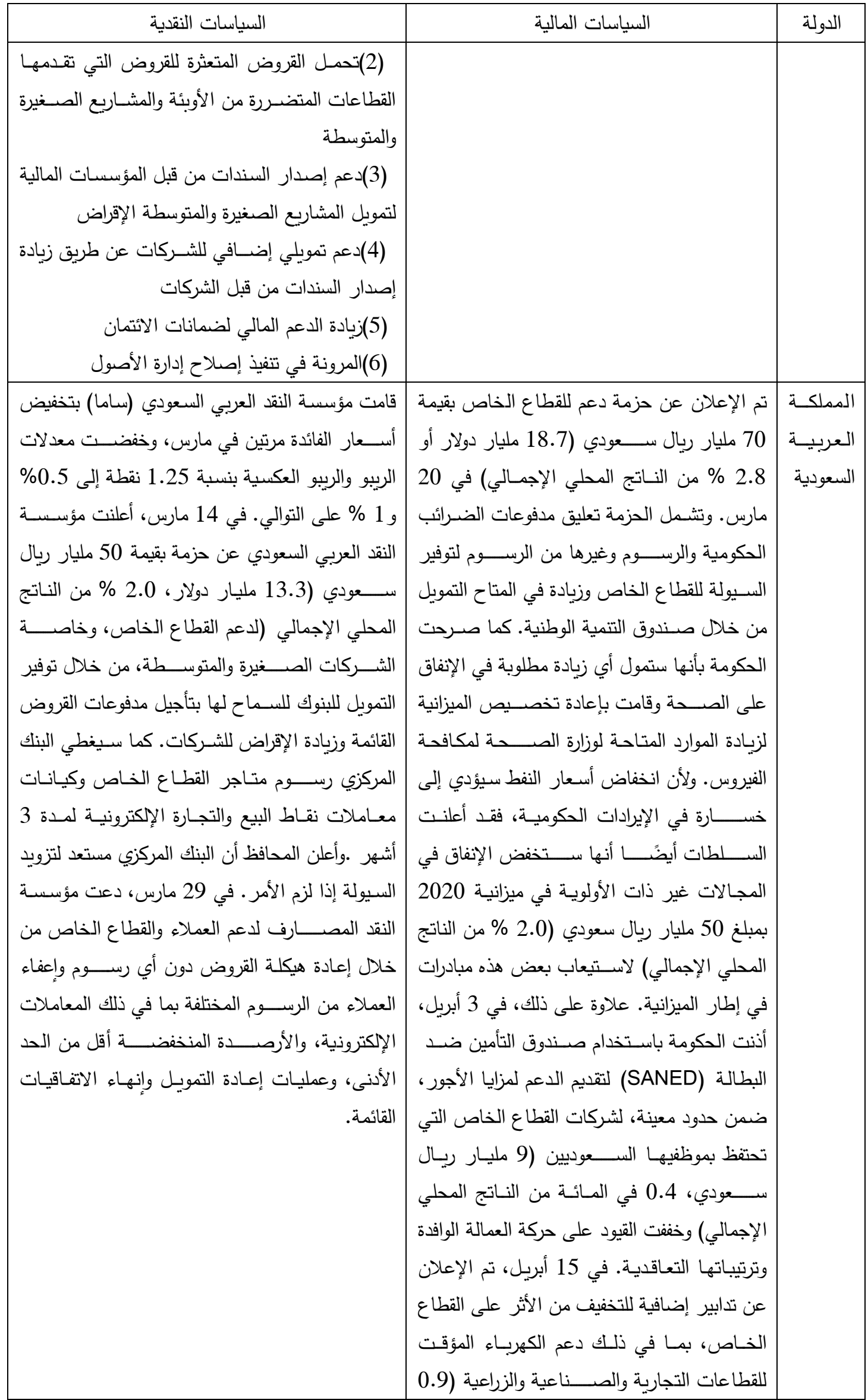




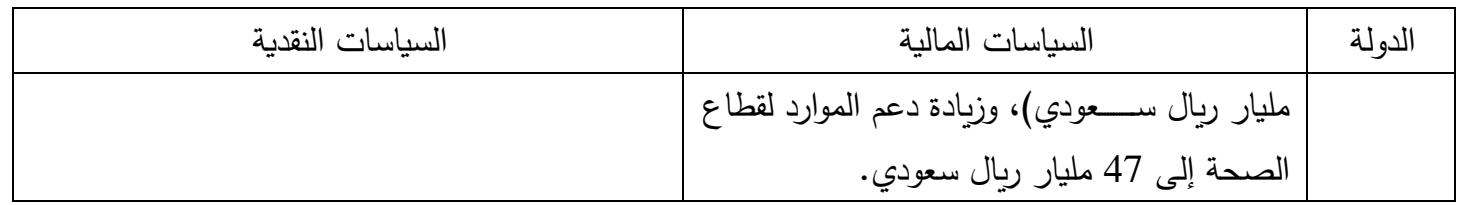

المصدر : موقع صندوق النقد الدولي، IMF Policy Tracer 
جدول (2): العلاقات بين المتغيرات الأساسية والفرعية لنموذج الدراسة

\begin{tabular}{|c|c|c|}
\hline وحدات القياس & المعادلة/ القيمة & المتغير/ المعلمة \\
\hline 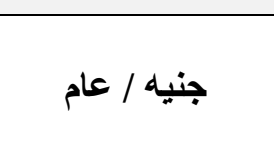 & 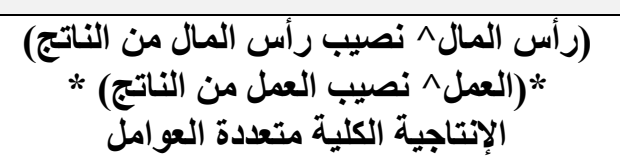 & الناتج المحلي الإجمالي \\
\hline جنيه مصري & 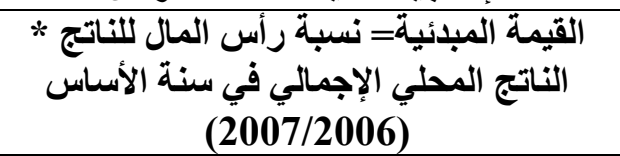 & Capital \\
\hline جنيه/ عام/ عوامل & 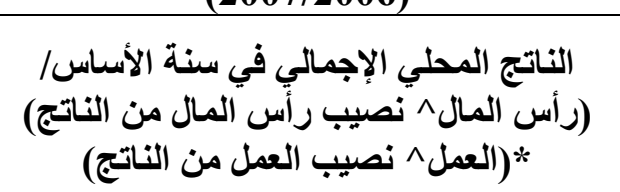 & $\begin{array}{l}\text { Total Factor Productivity } \\
\text { (TFP) الإنتاجية الكلية متعدة العوامل }\end{array}$ \\
\hline جنيه مصري & الاستثمارات العامة + الاستثمارات الخاصة & $\begin{array}{l}\text { Total Investment } \\
\text { الاستثمارات الكلية }\end{array}$ \\
\hline جنيه مصري & محسوب وفقاً لمعادلة رقم 1 & $\begin{array}{c}\text { Private Investent } \\
\text { الاستثمارات الخاصة }\end{array}$ \\
\hline جنيه مصري & 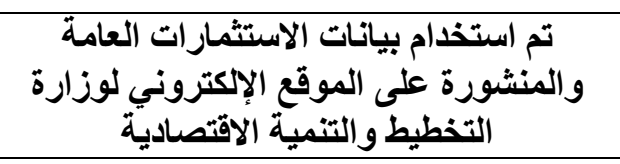 & $\begin{array}{l}\text { Public Investment } \\
\text { الاستثمارات العامة }\end{array}$ \\
\hline جنيه مصري & رأس المال / متوسط عمر رأس المال & $\begin{array}{l}\text { Depreciation } \\
\text { مeلإل معلاكل }\end{array}$ \\
\hline فرد - اد & قوة العمل * معدل التثثغيل & التوظيف \\
\hline $1 / 1$ & 0.75 & $\begin{array}{l}\text { Capital Income share } \\
\text { نصيب رأس المال من الناتج }\end{array}$ \\
\hline $1 / 1$ & $1-0.75$ & $\begin{array}{l}\text { Labor Income share } \\
\text { نصيب العمل من الناتج }\end{array}$ \\
\hline 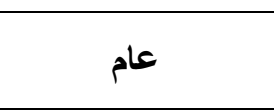 & وذلك وفقاً لنتائج المحاكاه 25 & $\begin{array}{c}\text { Capital Age } \\
\text { متوسط عمر رأس المال }\end{array}$ \\
\hline $1 / 1$ & $1.9 \%$ & $\begin{array}{l}\text { Total Factor Productivity } \\
\text { Growth rate } \\
\text { معدل نمو الإتتاجية الكلية للعوامل }\end{array}$ \\
\hline$\%$ & 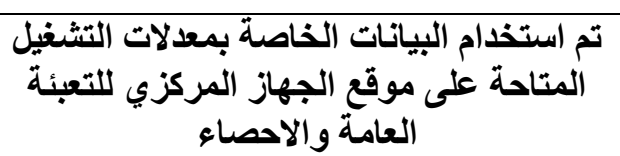 & $\begin{array}{c}\text { Employment Rate } \\
\text { معدل التثغيليل }\end{array}$ \\
\hline جنيه مصري/ دولار & 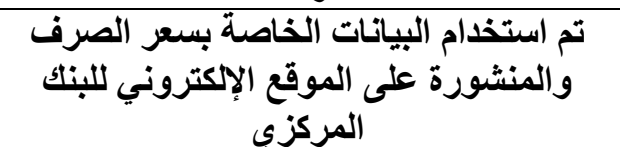 & $\begin{array}{c}\text { Exchange Rate } \\
\text { سعر الصرف }\end{array}$ \\
\hline$\%$ & والمنشورة على الموقع الإلكتروني اللبنتك & $\begin{array}{c}\text { Interest Rate } \\
\text { سعر الفائدة }\end{array}$ \\
\hline$\%$ & 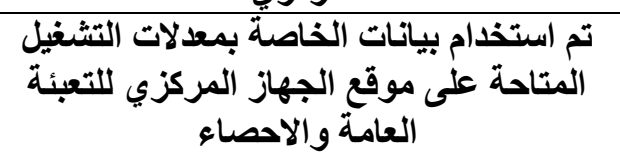 & $\begin{array}{c}\text { Inflation Rate } \\
\text { معدل التضخم }\end{array}$ \\
\hline
\end{tabular}

